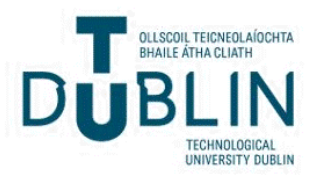

Technological University Dublin ARROW@TU Dublin

Articles

2020-06-01

\section{Leniency and Damages: Where Is the Conflict?}

Catarina Marvao Dr.

Technological University Dublin, catarina.marvao@tudublin.ie

Paolo Buccirossi

$L E A R$, Italy

Giancarlo Spagnolo

SITE-Stockholm School of Economics, University of Rome "Tor Vergata", EIEF, CEPR

Follow this and additional works at: https://arrow.tudublin.ie/creaart

Part of the Industrial Organization Commons

\section{Recommended Citation}

Paolo Buccirossi, Catarina Marvão, and Giancarlo Spagnolo, Leniency and Damages: Where Is the Conflict?, The Journal of Legal Studies 2020 49:2, 335-379

This Article is brought to you for free and open access by ARROW@TU Dublin. It has been accepted for inclusion in Articles by an authorized administrator of ARROW@TU

Dublin. For more information, please contact arrow.admin@tudublin.ie, aisling.coyne@tudublin.ie, gerard.connolly@tudublin.ie.

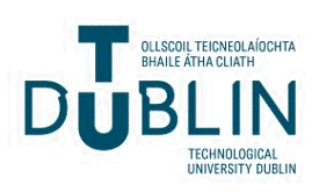




\title{
Leniency and Damages: Where is the Conflict?*
}

\author{
Paolo Buccirossi ${ }^{\dagger}$, Catarina Marvão ${ }^{\ddagger \S}$ and Giancarlo Spagnolo $\$$, \\ $\dagger$ Lear - Laboratorio di economia, antitrust, regolamentazione, Italy \\ ${ }^{\ddagger}$ SITE-Stockholm School of Economics \\ ${ }^{\S}$ Technological University Dublin - City Campus \\ ${ }^{\natural}$ Tor Vergata and Eief, Rome; CEPR London
}

August 24, 2020

Damage actions may reduce leniency programs' attractiveness for cartel participants if their cooperation with the competition authority increases the chance that the cartel's victims will sue them. This apparent conflict between public and private antitrust enforcement led to calls for a legal compromise. We show that the conflict is due to the legislation and a compromise is not required: limiting the victims' ability to recover their loss is not necessary to preserve the effectiveness of leniency programs and may be counterproductive. We show that damage actions will actually improve its effectiveness, if the civil liability of the immunity recipient is minimized and full access to all evidence collected by the competition authority, is granted to claimants. Our results help compare the EU and US damage systems and directly question the 2014 EU Directive which tries to protect leniency programs' effectiveness by restricting access to leniency statements in subsequent damage actions.

JEL Classification: D43, K21, K42, L13, L41

Keywords: Private and public enforcement, cartels, competition policy, Leniency Program

\footnotetext{
*We thank the three anonymous referees, Markus Dertwinkel-Kalt, Klaus Gugler, Kai-Uwe Kuhn, Margaret Levenstein, Janet Netz, Lily Samkharadze, Maarten Pieter Schinkel, Valerie Suslow and audiences at the University of Mannheim, the University of Michigan, IIOC 2015 in Boston, the MaCCI Annual Conference 2015 in Mannheim, the Swedish Workshop on Competition Research 2014 in Stockholm and the Veranstaltung Competition Law and Economics 2014 in Vienna for helpful comments. Marvão thanks the support of an ELEVATE Fellowship (ELEVATEPD/2013/29) Contacts: catarina.marvao@tudublin.ie (C.Marvão), paolo.buccirossi@ learlab.it (P.Buccirossi), giancaspagnolo@yahoo.com (G. Spagnolo; corresponding author)
} 


\section{Introduction}

Anti-cartel enforcement is central to antitrust and is its crucial component in terms of effects on a country's productivity growth (Buccirossi et al. (2013)). Cartels, however, remain a widespread phenomenon with serious consequences to society. ${ }^{1}$ Optimizing anti-cartel enforcement is therefore an important public policy issue.

Public and private competition law enforcement have complementary objectives and, in general, tend to reinforce each other. However, a conflict between them may arise in the fight against cartels. This conflict may be due to the central role played by leniency programs (LPs) in cartel probes. LPs provide a fine reduction (up to immunity) to cartel members in exchange for reporting the cartel and further cooperation with an investigation.

Private actions for damages may jeopardize LPs since a leniency application increases the risk of a successful damage action by the cartel's victims in two main ways. First, the evidence provided by the leniency applicant may be used by the claimants to prove the existence of the infringement and its effects.

Second, leniency applicants, and especially immunity recipients, normally do not challenge in court the infringement decision adopted by the competition authority (CA), at least as far as the existence of the cartel is concerned and, under joint liability they may be the first to be targeted. Therefore, the incentive stemming from the avoidance of a fine may be counterbalanced by the increased risk of being condemned to pay damages.

Two issues are particularly important for the interplay between LPs and private damages. The first issue is whether leniency applicants (and in particular, the immunity recipient) should have the same level and type of liability as all other cartelists. The second issue is whether access to the leniency statements and related documents should be granted to the claimants in the damage action.

\footnotetext{
${ }^{1}$ See Levenstein \& Suslow (2006) and Marshall \& Marx (2012), among others.
} 
These two issues go beyond the discretion that is attributed to competition authorities and need to be addressed through specific laws. Different solutions have been adopted in different jurisdictions.

In the US, victims of an antitrust infringement are entitled to treble damages and cartel members are jointly and severally liable for these damages. ${ }^{2}$ Moreover, the applicable discovery rules allow claimants in a damage action to obtain full disclosure of all relevant documents, including those provided by the leniency applicants. ${ }^{3}$

To reduce the risk of the effectiveness of the US LPs being undermined, the US Congress enacted the Antitrust Criminal Penalty Enhancement and Reform Act (ACPERA) in 2004. It eliminates treble damages and joint liability for the amnesty recipient (i.e. the first successful leniency applicant), who also has a duty to cooperate with the claimants in the civil action. Hence, the cooperating party is only exposed to own single damages, while the other conspirators remain jointly liable for the remaining, treble damages. ACPERA did not change the rules concerning the disclosure of relevant documents so that claimants can still rely on the evidence provided by the leniency applicants.

The new EU Directive (European Commission (2014)) disciplines the matter in the EU. ${ }^{4}$ With regards to liability, the Directive provides that the immunity recipient is jointly and severally liable as to its direct and indirect purchasers or providers. It is also liable to other injured parties but only if full compensation cannot be obtained from the other cartel members (Art. 11(4)).

With regards to access to documents submitted by a leniency applicant (not only the immunity recipient), the Directive provides that national courts cannot order the disclo-

\footnotetext{
${ }^{2}$ Note that although there are treble damages in the US, Lande (1993) has effectively argued that, even in the US, claimants are able to recover only a fraction of their actual losses.

${ }^{3}$ Note that, while judges do not request the leniency documents from the Department of Justice (DOJ), they can subpoena the firms and obtain all of the evidence a firm provided the DOJ with. This does not necessarily mean that there is always access to full evidence from the leniency statements for damage actions.

${ }^{4}$ The Directive has been fully transposed in the national legislation of all Member States. While the deadline was December 2016, 21 member states failed to meet this deadline and the last transpositions were implemented in March 2018 (Greece) and June 2018 (Portugal).
} 
sure of leniency statements and settlement submissions. (Art. 6(6)). Moreover, article 7(1) provides that Member States shall ensure that evidence in these two categories is either deemed to be inadmissible in actions for damages or is otherwise protected under the applicable national rules.

The fact that all LP statements and settlement submissions are "secreted" can be particularly worrisome in the light of an increasing number of cases in which the EC awarded some degree of leniency to - and then settled with - all cartel members (Marvão \& Spagnolo (2018b)). In these cases, the final decision will likely have a very limited informational content.

A rather interesting measure was adopted in Hungary in 2009, before the directive, where the immunity recipient was only liable for compensating the cartel's victims if and only if the other cartel members were unable to do so. ${ }^{5}$ To the best of our knowledge, this was the only jurisdiction in which the immunity recipient had liability of last resort. The protection granted to the immunity recipient did not prevent the access to the information and evidence provided to the competition authority. ${ }^{6}$

For simplicity, in the following we will refer to the three legal regimes described above as the US, the EU and the Hungarian solutions. The immunity recipient has full liability in the EU solution for direct and indirect damages and remains jointly liable to other injured parties only if the other cartelists cannot compensate these damages in full, detrebled and single (rather than joint and several) liability in the US solution and liability of last resort in the Hungarian one. The access to evidence is lower in the EU solution than in the US and Hungarian ones because in the EU the use of the evidence provided by the leniency applicants is prevented.

In this paper we theoretically analyze the interaction between these rules and the effectiveness of leniency programs in terms of the effects on general deterrence. Our

\footnotetext{
${ }^{5}$ Art.88D of the Hungarian Competition Act (1996), revised in 2009.

${ }^{6}$ The relevant information could be requested directly from the competition authority (or from the courts). Similarly to the US regime, this does not necessarily mean that there is always access to full evidence from the leniency statements for damage actions.
} 
theoretical analysis also allows us to examine whether the US, EU, and Hungarian solutions are appropriate, taking into consideration both the objective of preserving (or improving) the effectiveness of the LP and the objective of guaranteeing the right to compensation of the cartel's victims.

We investigate whether pursuing the primary goal of the public enforcement system, i.e. achieving an optimal level of deterrence of anti-competitive conducts, necessarily requires sacrificing the amount of damages that claimants can expect to recover, or whether, these two objectives can both be pursued in a consistent and complementary way, and if so to what extent and how. We focus on leniency awarded to parties that spontaneously report the cartel when the $\mathrm{CA}$ is unaware of its existence, since this type of leniency has unambiguously positive effects on deterrence, as long as sanctions are robust. ${ }^{7}$

In Spagnolo (2004), it is shown that, in order to maximize deterrence in the presence of a LP, it is optimal to minimize the amount of damages paid by the first (and only the first) leniency applicant. However, how much information from the leniency application has to be disclosed in the civil action and the right of victims to be compensated were not taken into account.

We extend Spagnolo (2004) to include these two additional elements. We determine the optimal combination of damage liability of the immunity recipient and the amount of information which should be accessible to the claimants (including leniency statements), both in terms of deterrence and of the ability of victims to be compensated. In doing so, we also take into account strategic risk as a novel deterrence channel, which recent experimental research has shown to be important for collaborative crimes like cartels. In the appendix, we provide suggestive evidence on the real world relevance of this deterrence channel from cartels recently convicted by the European Commission.

\footnotetext{
${ }^{7}$ On the contrary, leniency awarded when the CA is already aware of the cartel's existence has ambiguous effects (see Motta \& Polo (2003)). Hence, the reduction of fines granted by the European Commission to applicants that provide their collaboration after the launch of the investigation may be spurred by the desire to have access to evidence that strengthens the decision, like a substitute for plea bargaining, but may overall have a negative impact on deterrence (see Marvão \& Spagnolo (2015)).
} 
We find that, normally, there is no conflict between the two objectives, contrary to what is presumed in the legal debate. To maximize the attractiveness of the LP and deterrence, it is optimal to (a) minimize the amount of damages the immunity recipient is liable for, and (b) maximize the share of information collected by the competition authority and made accessible to the claimants, including leniency statements.

Therefore, we suggest a legal regime in which cartelists are jointly and severally liable toward all cartel's victims with the exception of the first successful leniency applicant who is kept immune from fines and civil liability in any case and independently of the other cartel members' ability to pay awarded damages in full. We also propose that full access to the leniency statements is granted to the claimants in the ensuing damage actions. In the following, this regime is referred to as "our proposal".

We then extend the model to include the cost of being the preferred target of the damage actions. We find that this extension further increases the efficiency gain of our proposal.

Our proposal and the Hungarian regime are identical in the case in which the immunity recipient is not required to pay awarded damages as the other cartelists have sufficient assets to do so. Hence, in order to assess the effectiveness of the two regimes in general we have to extend the analysis and consider the possibility of bankruptcy. We show that our proposal is still optimal in terms of deterrence. However, in this situation, a trade-off between deterrence and victims' rights for compensation may emerge. We show that, in this scenario, the Hungarian solution maximizes the value of expected liquidated damages while preserving deterrence in many cases. ${ }^{8}$

We then examine customers' welfare, leaving aside allocative efficiency considerations. We argue that the available evidence on bankruptcy risk, the share of recovered damages and the rate of cartel detection, are worthy reasons to presume that the benefit of our proposal, relatively to the Hungarian solution, is larger than its cost, even only

\footnotetext{
${ }^{8}$ Follow-on actions for damages may contribute to deterrence also by giving an incentive to cartels' victims to inform competition authorities of suspect behavior. This mechanism is not discussed in the paper as we focus on cartels that are uncovered through a LP.
} 
in terms of how many (actual and potential) cartel victims are likely to remain uncompensated.

The remainder of the paper is organized as follows. Section 2 relates this paper to the relevant economic and legal literature. Section 3 presents the theoretical model. Section 4 evaluates the different scenarios and discusses deterrence linked to both incentives to deviate and strategic risk, under the assumption of no bankruptcy. Section 5 examines the case in which firms' assets may be insufficient to cover the damages they are liable for. Section 6 discusses the impact of being the preferred target in damage actions, and the trade-off between deterrence and compensation. Section 7 concludes. All proofs and derivations are in the Appendix.

\section{Literature review}

The possible conflict between public and private enforcement has originated a long and ongoing debate in many jurisdictions. In the EU, this culminated with the 2014 Directive. In this section, we review this legal debate and the economic literature on the trade-off between public and private enforcement.

\subsection{The recent legal debate}

\subsubsection{Pre-directive EU damages' system}

Before the adoption of the Directive, the issues of liability of the immunity recipient and access to leniency statements, were dealt with by applying some general legal principles.

The first relevant principle, as stated by the European Court of Justice (ECJ) in the Manfredi (2006) and Courage (2001) judgements, is that the victims of an antitrust infringement have the right to be fully compensated for the harm they suffered. ${ }^{9}$ If

\footnotetext{
${ }^{9}$ Judgement of the Court of Justice of 13 July 2006, joined cases C-295/04 to C-298/04, Manfredi, ECR I-6619; and judgement of the Court of Justice of 20 Sept. 2001, case C-453/99, Courage, ECR I-6297.
} 
a more favorable treatment of an immunity recipient with respect to its civil liability hindered the effective exercise of this right to full compensation, it would run against this principle.

With regards to the access to the leniency statements, in a judgement concerning a referral from the district court of Bonn in Germany (Pfleiderer case) the ECJ ruled that EU law does not prohibit a third party, who has been adversely affected by a breach of competition law, from having access to a leniency application by the infringer. ${ }^{10}$ The court held that it is for the national judge to determine the conditions under which access to leniency material can be granted to someone seeking to obtain damages.

According to the ECJ, the national judge would need to take into account and weigh all the interests protected by EU law, namely the need to ensure the effectiveness of LPs and to support antitrust damage actions. ${ }^{11}$ This position has been confirmed in the more recent Donau Chemie judgement, where the ECJ affirmed that national courts must balance these possibly conflicting interests on a case-by-case basis, taking into consideration all the relevant facts of the case. ${ }^{12}$

\subsubsection{Legal literature}

Jurisdictions around the world are increasingly making efforts to improve private enforcement tools and cases of private cartel damages are on the rise. However, the legal debate remains active regarding the coexistence of private and public enforcement (eg. Shavell (1997), Segal \& Whinston (2007), Lande \& Davis (2011) and Bernard (2012))..$^{13}$

\footnotetext{
${ }^{10}$ Judgement of 14 June 2011 in the case C-360/09.

${ }^{11}$ On 30 January 2012, the German court which had brought the case before the ECJ concluded that access to leniency documents should be denied.

${ }^{12}$ Case C-536/11 - Bundeswettbewerbsbehörde v Donau Chemie AG and others.

In the light of these judgements it would be interesting to understand whether the European Court of Justice will consider the rule that impedes access to leniency statements a "balanced" solution that correctly takes into account the fundamental right of the victims to full compensation, as affirmed in the Manfredi and Courage judgments.

${ }^{13}$ The question of whether private enforcement should be added to public enforcement is not within the scope of this paper and an extensive survey on private and public enforcement of antitrust law can be found in Segal \& Whinston (2007). However, private enforcement is always beneficial if courts are sufficiently
} 
Shavell (1997) was one of the first to explore the differences between the social and private incentives to litigate from a legal perspective. He argues that achieving a number of litigations which is neither socially excessive nor socially inadequate requires corrective social policies and the guarantee that the claimants have more knowledge than the public regulators have or could possibly obtain. The author points out that low litigation costs allow more plaintiffs to access justice but encourages them to sue firms even in cases where the social costs exceed the social benefits.

In the $\mathrm{EU}$, the legal debate has been particularly active regarding the interaction between LPs and damage claims. This is closely related to the question posed in this paper. Cauffman (2011) and MacCulloch \& Wardhaugh (2012) suggest that the effectiveness of leniency should prevail and, therefore, the leniency applications should not be disclosed, whereas Komninos (2011) proposes a case-by-case approach. In addition, Komninos (2011) and Cauffman (2011) suggest that the immunity recipient should have limited liability. These proposals are somewhat in line with what has been approved in the 2014 Directive.

Two other papers examine the Directive itself. In line with the results of our formal analysis, Kortmann \& Wesseling (2013) and Geradin \& Grelier (2013) view the Directive as being flawed in the sense that the liability of immunity recipients should be further reduced.

\subsection{Economic literature}

Bourjade et al. (2009) study, theoretically, the effect of encouraging private actions for breaches of EU competition law by developing a model of litigation and settlement with information asymmetry. The authors conclude that it is better to increase damages than to reduce the cost of suing.

McAfee et al. (2008) develop a theoretical model which compares private and pubaccurate (McAfee et al. (2008)) and in this paper we assume this is the case. 
lic enforcement and find that, if the courts resolve with a low error level, then only legitimate suits are submitted and the optimal solution is the conjunction of public and private enforcement. This is because private parties have a better signal of the violation than the public agency. The authors assume that private and public entities' only choice is whether to sue the potential antitrust infringers and that public entities aim to maximize social welfare. In this scenario, they propose a system where private claimants pay a subsidy for public investigation in exchange for a monetary award following a conviction.

In line with our analysis is the theoretical model from Silbye (2012), which models the incentive to apply for leniency as a negative function of the total amount of damages that the leniency applicant is liable for. The author shows that antitrust damages, in the presence of a LP, can be pro-collusive if the leniency applicant is not given immunity also on damages.

More directly relevant to the analysis in this paper is Spagnolo (2004), which showed that eliminating liability for one LP applicant only (and awarding immunity to the first applicant only) is optimal from a purely general deterrence perspective. ${ }^{14}$ It also showed that distrust among cartel members, i.e. the fear of being reported by a co-conspirator, constitutes the main deterrence channel for collaborative crimes by introducing the concept of distrust (i.e. strategic risk). ${ }^{15}$

Bigoni et al. (2015b) provide experimental evidence on the power of this previously ignored deterrence channel for collaborative crimes, showing that cartel formation falls dramatically when a strict LP is introduced, even with communication and in the absence of public enforcement.

The paper is of course also related to other work in the recent but extensive literature on the economics of leniency programs, starting with the contributions by Motta \& Polo (2003), Aubert et al. (2006), Buccirossi \& Spagnolo (2006) and Harrington

\footnotetext{
${ }^{14}$ This proposal is also supported by some practitioners (see e.g. Green \& McCall (2009)).

${ }^{15}$ Leslie (2004) argued, from a legal point of view, that it is indeed important to take into account distrust among cartel members as a source of deterrence.
} 
(2008). A more comprehensive review of the empirical and experimental evidence on the effectiveness of LPs can be found in Marvão \& Spagnolo (2018a).

\section{A simple model}

We start by developing the simplest possible model from which to rigorously derive our results. This is both because our results are very intuitive - although only a formal analysis allows one to verify their robustness; and because we hope to reach the widest possible audience, including the legal and policy domains.

\subsection{The economic environment}

Consider an economy composed of a continuum of industries. In each industry, two symmetric firms produce a homogeneous good and repeatedly play a Bertrand game in the infinite, discrete time. Firms may choose to enter a collusive agreement to maintain a high price and escape the competitive outcome. If they do, and respect the agreement, each of them earns (at most) collusive profits $\Pi$ per period.

In each industry, firms share the same discount factor $\delta$. However, each industry has a different discount factor, for example because of different frequency of market interactions, and the different industry discount factors are distributed according to the c.d.f. $G(\delta)$ on the interval $\left(\frac{1}{2}, 1\right)$, so that absent law enforcement collusion is sustainable in equilibrium in every industry. ${ }^{16}$

We assume that to reach a collusive agreement firms need to communicate, that hard and compromising evidence is produced only after both firms agree to collude, and that this evidence, available to cartel members, can also be found by a CA that investigates the industry.

If a cartel forms between the two symmetric firms, the likelihood that the CA investigates, finds evidence on the collusive agreement and successfully prosecutes the

${ }^{16}$ With $\delta<\frac{1}{2}$ collusion is not sustainable, independently of antitrust enforcement. 
cartel members without any of them cooperating with the investigation (revealing information) is $\rho$, with $0<\rho<1$. A leniency program (LP) is in place, encouraging cartel members to self-report such hard evidence before any such investigation.

If a cartel is convicted because of an independent investigation by the CA, each member must pay a fine $F$ that, for simplicity, we assume is exogenously given, as in most previous analyses. If a cartel is convicted because one of the firms reported the hard information within the LP, the reporting firm becomes the immunity recipient and pays no fine while the other pays the full fine $F$. If both parties apply for leniency, each of them pays half of the fine. ${ }^{17}$

In each period, the timing of the game is therefore as follows:

- Stage 1: Each firm chooses whether to enter into a collusive agreement. If at least one firm chooses not to collude, then competition "à la Bertrand" takes place and the game ends for that period. The competitive Nash equilibrium generates zero profits for both firms. Otherwise:

- Stage 2: Each of the firms chooses whether to respect the agreement and "collude", quoting the agreed upon price, or to deviate from it, undercutting the agreed upon price. Firms can also choose whether to apply to the LP and report the cartel to the CA. If at least one of the firms applies, the game ends for the period. Otherwise:

- Stage 3: The CA chooses which industries to investigate, $\rho$ realizes, and the game ends for the period.

Figure 1 shows a graphical representation of the stage game.

\footnotetext{
${ }^{17}$ The underlying assumption is that if both firms decide to report the cartel to the CA they have the same probability of being the first successful leniency applicant.
} 
Figure 1: Graphical representation of the stage game

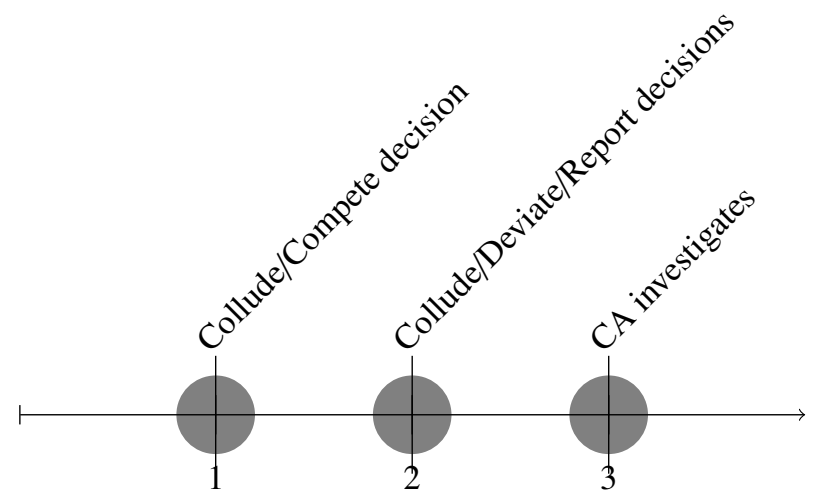

\subsection{Legal regimes for damage claims}

In addition to fines, cartel members are liable for compensation of buyers. The maximum amount of damages for each firm is $D$, so that the maximum amount of damages for which the cartel is liable is $2 D$. The fraction of these maximum total damages that each convicted firm will have to pay if the cartel is convicted, depends on the liability rules defined by the legislation and on the amount of information on the cartel available to the plaintiffs suing for damages in the various situations.

Remark 3.1 Given that the total amount of damages parties are liable for $(2 D)$ differs across countries (e.g. the US have treble damages whereas the EU Damage directive allows only for single damages), our analysis is intended as a within country comparison of legal rules - e.g. how deterrence would change in the US if it adopted the Hungarian solution, keeping the remaining features of US enforcement unchanged. It should not be intended as a general comparison of deterrence of overall legal enforcement across countries.

We denote by $W$ the total value of each firm's assets, so that the maximum value of damages that each firm is able to pay is $W-F=\gamma D$ (where $F=0$ for the immunity 
recipient). Then, $\gamma$ is defined by this equality as the share of direct damages that each firm is able to pay. We assume that $W>F$, both because it is realistic and to better focus on the effects of liability rules for damages when bankruptcy is an issue.

We denote the amount of damages a given firm is liable for by $D^{N R}$ if no firm reports under the LP; by $D^{R}$ if the firm reports under the LP but the other cartel member does not; $D^{O R}$ if only the other cartel member reports the cartel under the LP; and $D^{B R}$ if both do. In order to determine these values, we introduce the variables that represent the two features of the legal regime whose effects we want to investigate.

The first variable is denoted by $l \in[0,2)$ and represents the extent to which the immunity recipient is kept liable for damages, so that $l=0$ represents the case in which the first successful leniency applicant is fully immune also on civil grounds and $l=1$ identifies the case in which he does not obtain any reduction of his civil liability but is not jointly and severally liable for the damages caused by the other cartelist. Note that $l$ may be larger than 1 if the leniency applicant remains liable towards the purchasers of the other cartelist and the latter does not have enough assets to pay direct damages in full.

The second variable is denoted by $\alpha$ and represents the amount of information that is available to claimants. In particular, the various regimes differ with respect to the accessibility of the documents provided by the leniency applicant.

The parameter $\alpha$ can take two values: $\alpha^{N R}$ and $\alpha^{R} . \alpha^{N R}$ is the amount of information that claimants have if no firm applies for leniency; we assume that $0<\alpha^{N R}<1$, i.e. even if the cartel is uncovered by an autonomous investigation by the agency, and there is no leniency applicant, the victims are still able to obtain information from the standard proceedings, leading to a positive fraction of the damages being paid to the litigants. The assumption implies that there is always room for improvement. This element does not depend on the legal regime as the differences we are considering only concern whether claimants can use the leniency documents. 
The parameter $\alpha^{R}$ is the amount of information that claimants can use in the action if they have access to the documents provided by the leniency applicant; we assume that this additional source always improves the position of claimants and therefore that $\alpha^{N R}<\alpha^{R} \leq 1$.

We can now specify the value of $D^{N R}, D^{B R}, D^{R}$ and $D^{O R}$ as follows:

$$
\begin{aligned}
D^{N R} & =\alpha^{N R} D ; \\
D^{B R} & =\alpha^{R} D ; \\
D^{R} & =l \alpha^{R} D ; \\
D^{O R} & =2 \alpha^{R} D-D^{R} ;
\end{aligned}
$$

We consider four legal regimes, where necessary indexed by $L \in\{E, U, H, O\}$, where $E$ is the regime set in the EU by the Directive, $U$ is the US regime, $H$ is the Hungarian one and $O$ is our proposal. Throughout the analysis, we refer to the "solution" in each of these regimes as expressions to describe the legal choices concerning the treatment of the policy variables $l_{L}$ and $\alpha_{L}^{R}$, rather than the entire legal regime. So, each regime is described by a pair $L=\left(l_{L}, \alpha_{L}^{R}\right)$. The four regimes can be described as follows.

The EU regime sets $\alpha_{E}^{R}=\alpha^{N R}$ (because it prevents the disclosure of the evidence provided by the leniency recipient). As for the other policy variable, the EU regime sets $l_{E}=1$ if the other cartelist can pay direct damages and $l_{E}=2-\frac{\gamma}{\alpha^{N R}}$ otherwise. Hence this rule can be written as $l_{E}=\max \left\{1,2-\frac{\gamma}{\alpha^{N R}}\right\}$. The US regime sets $l_{U}=\frac{1}{3}$ (because damages are detrebled for the leniency applicant who can also avoid joint and several liability) and $\alpha_{U}^{R}=\alpha^{R}$ (because judges can subpoena the firms and obtain all the evidence a firm provided the DOJ with). In the Hungarian regime, we have that $\alpha_{H}^{R}=\alpha^{R}$ and $l_{H}=\max \left\{0,2-\frac{\gamma}{\alpha^{R}}\right\}$ (because the leniency applicant is immune from civil liability if the other cartelist can pay damages in full but remains joint and several liable towards 
all claimants otherwise). Finally, our proposal is to set $l_{O}=0$ and $\alpha_{O}^{R}=\alpha^{R}$.

Under the assumption of no bankruptcy $\left(\gamma \geq 2 \alpha^{R}\right)$, we have $\alpha_{O}^{R}=\alpha_{H}^{R}=\alpha_{U}^{R}=\alpha^{R}>$ $\alpha_{E}^{R}=\alpha^{N R}$ and $l_{E}=1>l_{U}=\frac{1}{3}>l_{H}=l_{O}=0$. Our proposal and the Hungarian solution are identical in this setting which will be analyzed in the next section. However, in section 5 we will extend the model to the case in which cartelists individually might be unable to pay damages in full. This condition introduces a distinction between our solution and the Hungarian one.

\section{Analysis}

In this section we will evaluate the effects of the different legal regimes on deterrence. We will first follow the approach standard in the literature that, following Stigler (1964), only focuses on the temptation to move to a non-cooperative equilibrium and posits that a cartel is deterred when the (no-deviation) incentive compatibility constraint for the cartel being an equilibrium is violated, so that collusion is not sustainable in equilibrium.

An important aspect the standard approach misses is the considerable existing evidence that each firm will also take into account the possibility and consequences of being betrayed by the other cartel members when deciding whether to take part in a cartel. A collusive agreement, to be viable, also requires that firms trust each other, that they have sufficient confidence that, in each future period each co-conspirator will stick to the collusive equilibrium and will not get "cold feet" and switch to competitive strategies, reporting the cartel to obtain a lenient treatment, possibly for fear that someone else would do that. In subsection 4.2 we will take this fully into account and show that some rather puzzling implications of the standard approach disappear.

We start by assuming that $\gamma \geq 2 \alpha^{R}$, so that even if only one firm is kept fully liable, its assets suffice to pay the maximum total cartel damages $\left(2 \alpha^{R} D\right)$. While we consider this a realistic assumption, particularly for large cartels, in Section 5 we consider the 
alternative case of damages potentially leading cartel members into bankruptcy. For simplicity, it is also assumed that firms do not appeal decisions.

\subsection{Deterrence as absence of collusive equilibria}

To sustain collusion, agents use a grim-trigger strategy, which is reversion to a permanent competitive Nash equilibrium, in case of deviation. The environment is stationary, so if no deviation is observed, firms continue to collude after they are convicted by a random investigation by the CA. ${ }^{18}$

If the fine is sufficiently high, in all legal regimes a firm that deviates by undercutting the collusive price also finds it optimal to apply to the LP at the same stage (Stage 2) ${ }^{19}$ To see this consider that a firm which deviates and reports the cartel to the CA obtains the following short-run payoff: $2 \Pi-l \alpha^{R} D$, whereas a firm which deviates without reporting obtains $2 \Pi-\rho\left(\alpha^{N R} D+F\right)$. Hence "deviate and report" is preferred to "deviate without reporting" if $l \alpha^{R} D \leq \rho\left(\alpha^{N R} D+F\right)$. If $l=0$, as in our proposal and the Hungarian solution, this condition is obviously satisfied independently of the severity of the fine.

This condition also holds in the EU regime if $\rho F \geq \alpha^{N R} D(1-\rho)$ and in the US regime if $\rho F \geq D\left(\frac{\alpha^{R}}{3}-\rho \alpha^{N R}\right)$ i.e. if the expected fine is higher than the increase in expected damages due to the leniency application. This threshold is certainly met if the fine is set optimally, in the sense that its expected value is equal or higher than the harm caused by the cartel.

Indeed, the previous condition can be rewritten as: $l \alpha^{R} \leq \rho\left(\alpha^{N R}+\frac{F}{D}\right)$. When $\rho F \geq D$, the right-hand side of this inequality is larger than 1 , whereas the left-hand

\footnotetext{
${ }^{18}$ This is as in Chen \& Rey (2013). The results would not change if we assumed that collusion would stop, temporarily or permanently, after a successful conviction of the cartel linked to a random investigation, without any deviation from the cartel partners.

${ }^{19}$ The theory of repeated games requires to focus on the optimal (most profitable) one-shot deviation from the cooperative path (see e.g. Fudenberg \& Tirole (1991)), and deviating and simultaneously reporting is the optimal deviation in a leniency context, given that the statute of limitations for cartel infringement is usually three to five years after the end of cartel behavior. Unfortunately, some old and new papers on this topic get this basic issue wrong, focusing on sub-optimal deviations, thereby deriving incorrect results and misleading policy implications.
} 
side is always weakly smaller than 1 , as, with no bankruptcy, $l, \alpha^{R} \in[0,1]$, and the condition is always satisfied. In any case, if the legal regime on fines is designed in a way that a firm's deviation payoff is higher if it does not report the cartel to the CA, then the LP is totally ineffective. Since we are interested in understanding which rules on civil liability make a LP more apt to deter cartels, we will assume that the expected fine is sufficiently high to make the above conditions true also in the EU and in the US regimes. ${ }^{20}$

Firms can therefore sustain a stationary collusive agreement in a subgame perfect Nash equilibrium if the expected gains from respecting the collusive agreement and not reporting are larger than the expected discounted gains from optimally deviating and applying for leniency.

If firms choose not to apply for leniency, they will earn in each period, a net profit of $\Pi$ minus the expected penalty $\left(F+D^{N R}\right)$. However, if a firm deviates and simultaneously applies for leniency, while the other firm complies, it will earn profits of $2 \Pi$ and it will receive fine immunity $(F=0)$, although it will still be liable for damages in the amount of $D^{R}$. The expected discounted values of colluding and not reporting the cartel $(N R)$ and of deviating and reporting $(R)$ are then, respectively:

$$
\begin{gathered}
V^{N R}=\frac{\Pi-\rho\left(F+D^{N R}\right)}{1-\delta} \\
V^{R}(L)=2 \Pi-D^{R}=2 \Pi-l_{L} \alpha_{L}^{R} D
\end{gathered}
$$

The incentive compatibility constraint (ICC) below, determines the minimum discount factor $\underline{\delta}(L)$ necessary for collusion to be sustainable in equilibrium:

$$
V^{N R}-V^{R}(L)>0 \leftrightarrow \delta>\underline{\delta}(L) \equiv 1-\frac{\Pi-\rho\left(F+D^{N R}\right)}{2 \Pi-D^{R}}=1-\frac{\Pi-\rho\left(F+\alpha^{N R} D\right)}{2 \Pi-l_{L} \alpha_{L}^{R} D} .
$$

\footnotetext{
${ }^{20}$ This assumption does not imply any loss of generality because in the EU and in the US regimes, if the leniency program is ineffective, the level of deterrence is always lower than the one which is achieved with an effective leniency program, as shown in Appendix 8.1.
} 
Since collusion is sustainable in equilibrium only in those industries where $\delta>\underline{\delta}$, an increase in $\delta$ increases cartel deterrence, as it directly reduces the number of industries that satisfy the condition for collusion to be an equilibrium. The analysis of this incentive constraint leads to our first result.

Proposition 1: The effectiveness of the leniency program in terms of deterrence, as measured by $\underline{\delta}(L)$, is smaller under the EU and the US solutions than under the Hungarian and our solutions.

Proof in Appendix 8.1.

The logic behind this result is very intuitive. Inspecting the incentive constraint, it is clear that $\underline{\delta}(L)$ increases when $l_{L} \alpha_{L}^{R}$ decreases, making the constraint more difficult to satisfy. Since deterrence increases with $\underline{\delta}$, to maximize deterrence (the set of industries in which a collusive equilibrium is not sustainable) $l_{L} \alpha_{L}^{R}$ should be set at its minimum, which is clearly $l_{L} \alpha_{L}^{R}=0$. Given that $\alpha_{L}^{R}$ belongs to the set $\left\{\alpha^{N R}, \alpha^{R}\right\}$, and $\alpha^{R}>\alpha^{N R}>0$, this minimum, and hence maximal deterrence, can only be achieved by limiting immunity recipients' liability, i.e. by setting $l_{L}=0$ as we suggest. The Hungarian solution is also optimal if there is no risk of bankruptcy, as assumed in this basic version of the model, because it sets $l_{H}=0$ such that $D^{R}=0$.

Conversely, the legal regime determined by the US solution leads to a sub-optimal level of deterrence in that jurisdiction because it sets $l_{U}=\frac{1}{3}$ and $\alpha_{U}^{R}>\alpha^{N R}$.

It is noteworthy that if the immunity recipient's liability can not be minimized (i.e. $l_{L}>0$ ), then reducing the amount of information victims can access and use in private damage suits (in particular, leniency statements), e.g. setting $\alpha_{L}^{R}=\alpha^{N R}$, as done by the EU Directive, can lead to increased deterrence.

While simple, intuitive and in line with the literature, this standard analysis with deterrence measured by how tight the incentive constraint is, indexed by $\underline{\delta}$, hence by 
the fraction of industries in which a collusive equilibrium exists, has limitations that lead to rather counter-intuitive implications.

Puzzle 1: When the amount of damages the immunity recipient is liable for is set optimally $\left(l_{L}=0\right)$, the liability of colluding firms that did not apply for leniency $\left(D^{O R}\right)$ is irrelevant for optimal deterrence, as it does not appear in the incentive constraint.

Puzzle 2: When the amount of damages the immunity recipient is liable for is set optimally, the amount of information available to victims after conviction $\left(\alpha_{L}^{R}\right)$ is irrelevant for optimal deterrence, as if $l_{L}=0$ then $l_{L} \alpha_{L}^{R} D=0$ for any $\alpha_{L}^{R}$.

These puzzling implications emerge because the damages expected by convicted non-leniency applicants do not enter the ICC. This unrealistic feature, shared by all models that focus on the cartel's ICC, was already noted in Spagnolo (2004) with respect to fines.

In the next subsection we will show that these puzzles disappear once we take into account that satisfying the incentive constraint is typically not sufficient to achieve and sustain cooperation/collusion. This is because potential cartel partners also need to coordinate and trust that the others will comply with the illegal agreement rather than betray them and apply for leniency. Experimental evidence indicates that this distrust is the main deterrence channel for well designed leniency programs.

Before moving in that direction, we note that our solution does not affect the right of cartel victims to be compensated. Indeed, in any case, victims obtain the total damages awarded by the court $\left(2 \alpha^{R} D\right)$. The only difference is that in this regime this payment comes from the other members of the cartel and not the immunity recipient $\left(D^{R}(O)=0\right.$ and $\left.D^{O R}(O)=2 \alpha^{R} D\right)$. 


\subsection{Accounting for strategic risk}

In the previous subsection we assumed that the collusive agreement is sustained as long as the ICC is satisfied. In other words, we assumed that coordination on the collusive agreement is always perfect and that the viability of collusion only depends on each member's own incentives to deviate (as analyzed by the ICC), i.e., the risk of being reported by the other cartel member(s) being nonexistent in each and every period of the cartel's life and beyond.

Spagnolo (2004) models strategic risk, which can be interpreted as the risk of miscoordination between the collusive and non-collusive equilibria. ${ }^{21}$ After communicating and coordinating initially, firms playing collusive strategies and playing the noncollusive strategy (which includes reporting if a cartel was present), and then continuing to compete remain continuation equilibria of each and every future period in the cartel's life. It is possible that in any of these periods one player may switch to the non-collusive equilibrium, since even if collusion is an equilibrium, individuals can be discouraged from sticking to collusive strategies by the fear of miscoordination from the other players.

This selection criterion predicts behavior better than Pareto dominance and since the underlying force comes entirely from the strategies played by the other firm(s), it is naturally defined "strategic risk". A simple example can be found in Appendix 8.3.

In the presence of leniency (LP), this includes the risk of being betrayed by some other cartel member who, any time during the cartel's life, might abandon the collusive equilibrium for the non-collusive one, for any reason, including the fear than someone else might do it. When taken into account in the model, this concern may constitute the tightest constraint for collusion to be viable, becoming the main deterrence channel for collaborative crimes. A strict LP (offering amnesty only to the first reporter), together with sufficiently large fines for the remaining cartel members, may increase

\footnotetext{
${ }^{21}$ The game theoretic foundations of this concept have been developed in Blonski et al. (2011) and Blonski \& Spagnolo (2015).
} 
the loss from colluding while an opponent does not. This loss may make the option of switching to competition and reporting first safe and attractive relative to incurring the risk of being reported by another cartel member switching to competition, even though sustaining collusion would be more profitable. A LP may then make the activity become too risky to be undertaken in the first place.

Explicit communication may not be able to solve this problem because a wrongdoer would gain by persuading its partner to trust him even if he plans to switch to the non-cooperative equilibrium. ${ }^{22}$

Bigoni et al. (2015b) provide experimental evidence on the power of this deterrence channel for collaborative crimes, showing that cartel formation falls dramatically when a strict LP is introduced, even with communication and in the absence of public enforcement. This is because, with leniency, deterrence appears to be mainly driven by an increased fear of being reported by other cartel members, or distrust. Therefore, by increasing the cost of being betrayed by a partner in crime, the LP can generate a higher demand for trust among criminals, and thus less crime for any given level of initial trust. ${ }^{23}$

There is also suggestive real world evidence that confirms the laboratory evidence on the importance of distrust for colluding firms. In Appendix 8.2, we present several cases where the importance of distrust, and more generally of concerns about other cartel members' behavior clearly emerge from cartel members' communication as reported in the European Commission decisions.

In this subsection, we follow these recent advancements by also taking into account distrust as a deterrence channel. We check whether and how the results of the previous

\footnotetext{
${ }^{22}$ Pre-play communication (i.e. cheap talk) can help solve the coordination problem in a pure coordination game when the message is self-committing (i.e. the sender has an incentive to stick to the message if the opponent believes it) and self-signaling (i.e. it is in the sender's best interest to send a true message). However, this game is not a pure coordination game, and the presence of a LP makes cheap talk not self-signaling. Therefore, the selection of the cooperative equilibrium hinges on the parties' mutual trust(Buccirossi, 2008).

${ }^{23}$ Additional experimental evidence of the importance of this type of distrust for cooperation/collusion in infinite repeated games was found by Dal Bó \& Fréchette (2011, 2018), Blonski et al. (2011) and Breitmoser (2015), for infinitely repeated games, and by Bigoni et al. (2015a), Calford \& Oprea (2017) and Embrey et al. (2018) for finitely repeated and continuous time ones.
} 
section change in its light.

The analysis shows under which circumstances all cooperation equilibria are risk dominated by the non-collusive equilibrium. ${ }^{24}$ The collusive equilibrium is more profitable than the competitive one, but it exposes the firm to the risk of miscoordination, a particularly costly event in the presence of a LP, as the opponent will then also report the cartel to the CA. Following Spagnolo (2004), Blonski et al. (2011) and Blonski \& Spagnolo (2015) we can then derive a minimum level of the discount factor $\delta^{*}$ necessary for the higher strategic risk of a collusive equilibrium to be dominated by the higher expected profits, so that subjects choose to collude.

To derive $\delta^{*}$, in Appendix 8.3 we calculate the riskiness of the collusive agreement, obtaining that collusion is risk dominated by reporting when

$$
\delta>\delta^{*}(L) \equiv 1-\frac{V^{N R^{\prime}}}{\frac{3 V^{R}(L)-V^{O R}(L)}{2}}=1-\frac{\Pi-\rho\left(F+\alpha^{N R} D\right)}{3 \Pi+\frac{F}{2}+\alpha_{L}^{R} D\left(1-2 l_{L}\right)},
$$

where $V^{N R \prime}$ is the numerator of $V^{N R}$.

This new threshold discount factor $\delta^{*}$ is larger than the $\underline{\delta}$, which is necessary for a collusive equilibrium to exist in the first place, as long as

$$
\frac{F}{2}+\left(1-l_{L}\right) \alpha_{L}^{R} D \geq 2 \Pi
$$

This condition is satisfied in the EU regime if $\frac{F}{2} \geq 2 \Pi$, in the US regime if $\frac{F}{2}+\frac{2}{3} \alpha^{R} D \geq 2 \Pi$ and in the Hungarian and our regime if $\frac{F}{2}+\alpha^{R} D \geq 2 \Pi$. Hence, if it holds in the EU regime it holds in all other regimes as well. We have to note that, in the ICC, $\Pi$ identifies the short-run gains from deviation. Therefore we can say that the critical discount factor stemming from strategic risk considerations is larger than the ICC critical discount factors in all regimes if the fine is at least four times the short run gains a firm can obtain by deviating from the collusive equilibrium. We believe

\footnotetext{
${ }^{24}$ Blonski \& Spagnolo (2015) show that the results do not change by moving away from full cooperation to e.g., inefficient equilibria (see section 5 in their paper).
} 
that this condition is likely to hold in all jurisdictions and for any cartel.

Indeed, the deviation gain only occurs for a "period" (i.e. until the deviation is detected and the punishment phase starts) whereas fines are set taking into account the whole cartel duration that may span over a number of years. Moreover, CAs should impose fines that exceed the overall collusive profits (over the entire cartel life) as they will be discounted, by firms, by the probability of detection and conviction.

Therefore, in the following we will assume that the fine is "meaningful", meaning that it is large enough to make condition (2) satisfied also in the EU regime. Note that our conclusions would be even stronger if we relax this simplifying assumption. Indeed, in this case the relevant threshold would be $\underline{\delta}(E)$ in the EU and $\delta^{*}(O)$ in the regime we propose, if the less stringent condition that makes (2) true in our regime holds. Since we already know that $\underline{\delta}(O)>\underline{\delta}(E)$ we can surely conclude that deterrence is stronger in our regime as $\delta^{*}(O)>\underline{\delta}(O)$. Given the assumption that the fine is "meaningful", maximizing deterrence while taking into account both incentives and strategic risk considerations amounts to maximizing $\delta^{*}$. By comparing $\delta^{*}$ in the various regimes we can state the following:

Proposition 2: Taking into account strategic risk (the fear of betrayal), cartel deterrence is:

a) decreasing in $l_{L}$;

b) increasing in $\alpha_{L}^{R}$ if $l_{L}<\frac{1}{2}$ and decreasing in $\alpha_{L}^{R}$ if $l_{L}>\frac{1}{2}$; and

c) strictly lower under the EU and the US solutions than under the Hungarian and our suggested solutions.

Proof in Appendix 8.4.

Taking distrust into account changes our previous conclusions in several ways.

First, the liability of colluding firms that did not apply for leniency $\left(D^{O R}\right)$, now 
does matter, as it determines the consequences of being betrayed by a co-conspirator. This "fixes" the first puzzling implication of the standard analysis. It also implies that minimizing $D^{R}$ is not only important for increasing the incentives to report and apply for leniency, but also because it shifts damage liability to cartel members other than the immunity recipient, increasing $D^{O R}$, and with it, distrust and deterrence.

Second, it shows that the amount of information available to claimants after conviction is no longer irrelevant for optimal deterrence. Even when the liability for damages of the immunity recipient is optimally set to $D^{R}=0$ (or when it is sufficiently low: $l_{L}<\frac{1}{2}$ ), deterrence increases strictly in the amount of information disclosed to the victims suing for damages $\left(\alpha_{L}^{R}\right)$. This is because deterrence is now mainly driven by an increased fear of being betrayed and reported, and not mainly by the liability of the immunity recipient, as before. By increasing the incentive to betray and the cost of being betrayed by another cartel member, in the presence of a LP, there is now a higher demand for trust amongst cartel members. This "fixes" also the second puzzling implication of the standard analysis mentioned in the previous subsection.

Proposition 2c) also indicates that, in principle, the effectiveness of the LP is further improved if the immunity applicant is asked to provide more information to the claimants, beyond the evidence given to the CA. This cooperation is captured by a value of $\alpha_{L}^{R}$ that is larger than $\alpha^{R}$ and, in our formal setting, the best policy choice would be to require the reporting firm to give all the information that is needed to guarantee that claimants obtain a complete compensation of the harm suffered, that is to set $\alpha_{L}^{R}=1$. However, one should bear in mind that this requirement would be very difficult to verify and this is likely to create some degree of uncertainty that may discourage a leniency application. Indeed, a similar choice is adopted in the US where the amnesty applicant must demonstrate it had rendered "satisfactory cooperation" to claimants and produced all documents or other items potentially relevant to the civil action. Yet, it has been argued that the lack of objective standards for measuring a company's coop- 
eration had the potential to seriously undermine the intended goals of the legislation. ${ }^{25}$ We do not formally address this issue that would need a completely different setting in which uncertainty about the success of the leniency application is introduced.

As before, if the liability of the immunity recipient cannot be minimized $\left(l_{L}>\frac{1}{2}\right)$, then even when distrust is taken into account, minimizing the amount of information available to claimants $\left(\alpha_{L}^{R}\right)$ can be optimal, as is done in the EU solution.

\section{The case of bankruptcy}

In this section we extend the analysis to consider the case in which firms' assets may be insufficient to compensate the cartel's victims. This is a relevant extension as our proposal and the Hungarian regime differ only if the non-reporting firm alone cannot cover the damages awarded by the court. To keep the analysis as simple as possible, we assume that each firm has a given amount of assets $(W>F)$ which remains the same in each and any period, as profits are distributed to shareholders before the fine is set and damages actions undertaken. Furthermore, we maintain the assumption of symmetry, meaning that firms have the same assets value.

We have defined $\gamma=\frac{W-F}{D}$ as the ratio between available assets, once the fine has been paid, and the damage attributable to each firm. In the previous section we consider the case in which $\gamma \geq 2 \alpha^{R}$, a condition that guarantees that in all legal regimes the nonreporting firm can pay damages in full. Now we evaluate the four legal regimes in the case in which the applicable rules and the level of assets are such that the non-reporting firm may go bankrupt, i.e. $\gamma<2 \alpha^{R}$. Henceforth, this occurrence will be defined as NRF, which stands for "non-reporting (firm) fails". For simplicity, we assume that if NRF the failed firm is immediately replaced by another identical firm which follows the same strategy and competes in the market. This ensures that the competitive conditions

\footnotetext{
${ }^{25}$ See for instance the submission of the ABA to the Public Roundtable on Antitrust Criminal Penalty Enhancement \& Reform Act (ACPERA) held by the US DOJ, available at https://www.justice.gov/atr/page/file/1168676/download\#American\%20Bar\%20Association\%20(ABA)
} 
in the market do not change.

First of all we need to redefine the Hungarian legal regime. The policy variable that changes is the one that defines the liability of the leniency applicant, $l_{H}$. In the new scenario, this variable becomes $l_{H}=2-\frac{\gamma}{\alpha^{R}}$, as the reporting firm is liable for all damages that cannot be paid the other cartelist.

Since we are interested in understanding the effects on deterrence of the LP in the different regimes, in this section we assume that applying for leniency remains a viable option in all cases. This means that the reporting firm does not fail. This requires that $W \geq l_{L} \alpha_{L}^{R} D$ for any $L$. Since $F=0$ for the leniency applicant, the latter condition can be written as $\gamma \geq l_{L} \alpha_{L}^{R}$. This is always satisfied in our proposal, as $l_{O}=0$. In the other regimes this condition becomes: $\gamma \geq \alpha^{N R}$ (EU), $\gamma \geq \frac{\alpha^{R}}{3}$ (US) and $\gamma \geq \alpha^{R}$ (Hungarian). The most stringent condition is the one that arises in the Hungarian regime. Therefore in the following we assume that $\alpha^{R} \leq \gamma<2 \alpha^{R}$. With this assumption the other regimes remain the same as in the previous section, since the liability rules do not depend on the NRF condition. In Appendix 8.5 we will briefly discuss the other cases.

If $\gamma \epsilon\left[\alpha^{R}, 2 \alpha^{R}\right)$, it is easy to verify by inspection that the expected discounted values of colluding and not reporting the cartel $\left(V^{N R}\right)$ and of deviating and reporting $\left(V^{R}(L)\right)$ are unaffected. Hence the proof of Proposition 1 remains valid and Proposition 1 holds for our proposal while the Hungarian solution is no longer optimal as $l_{H}$ is strictly positive. $^{26}$

To assess the degree of deterrence in the various legal regimes taking into account strategic risk, we need to compute the value of the continuation game for the nonreporting firm, $V^{O R}(L)$. Given that the non-reporting firm pays damages up to its available assets we have:

$$
V^{O R}(L)=-F-\min \left\{W-F ;\left(2-l_{L}\right) \alpha_{L}^{R} D\right\} .
$$

\footnotetext{
${ }^{26}$ The Hungarian solution works better than the EU one iff $\gamma>2 \alpha^{R}-\alpha^{N R}$ and better than the US iff $\gamma>\frac{5}{3} \alpha^{R}$.
} 
It is immediate to check that $V^{O R}=-W$ in both our solution and the Hungarian one, since the non-reporting firm always fails (NRF, by definition). In the EU regime $V^{O R}(E)=-F-\alpha^{N R} D$ as NRF never occurs since $\gamma \geq \alpha^{R}>\alpha^{N R}$. Finally in the US regime, NRF if $\gamma \leq \frac{5}{3} \alpha^{R}$ so that $V^{O R}(U)=-F-\min \left\{W-F ; \frac{5}{3} \alpha^{R} D\right\}$.

Using the above formulas and those for $V^{N R}$ and $V^{R}(L)$ we can compute the critical discount factors $\delta^{*}(L)$ in the various regimes. Notice that $\delta^{*}$ now has kinks where NRF so that the analysis cannot be done by simply computing derivatives. Hence the proof, although very simple, becomes more cumbersome. The various $\delta^{*}(L)$ are derived in Appendix 8.5 where we also complete the proof of the following:

Proposition 3: If $\alpha^{R} \leq \gamma<2 \alpha^{R}$, taking into account strategic risk, cartel deterrence is:

a) always higher under our proposed solution than in any other legal regimes;

b) always higher in the US regime than in the EU regime;

c) higher in the Hungarian regime than in the US regime if $\gamma>\frac{5}{3} \alpha^{R}$ and lower if $\gamma<\frac{5}{3} \alpha^{R}$

d) higher in the Hungarian regime than in the EU regime if $\gamma>\frac{3}{2} \alpha^{R}-\frac{1}{2} \alpha^{N R}$ and lower if $\gamma<\frac{3}{2} \alpha^{R}-\frac{1}{2} \alpha^{N R}$.

This proposition can be represented graphically as in figure 2. The space $\left(\alpha^{R}, 2 \alpha^{R}\right)$ has been divided in three regions: $A=\left(\frac{5}{3} \alpha^{R}, 2 \alpha^{R}\right) ; B=\left(\frac{3}{2} \alpha^{R}-\frac{1}{2} \alpha^{N R}, \frac{5}{3} \alpha^{R}\right)$ and $C=\left(\alpha^{R}, \frac{3}{2} \alpha^{R}-\frac{1}{2} \alpha^{N R}\right)$. Below each of them we report the ranking of the four legal regimes in terms of deterrence.

The proposition and figure 2 show that there is a clear winner (the regime we propose) but that there is not a clear looser, as the Hungarian solution progressively becomes worse than the others. To understand this result, consider that if strategic risk matters (as we maintain), deterrence depends on the combination of two elements: 1) the attractiveness of the LP for the first leniency applicant, which in turn depends on 
the protection granted to the immunity recipient; and 2) the loss suffered by the firm that is betrayed.

Figure 2: Graphical representation of Proposition 3

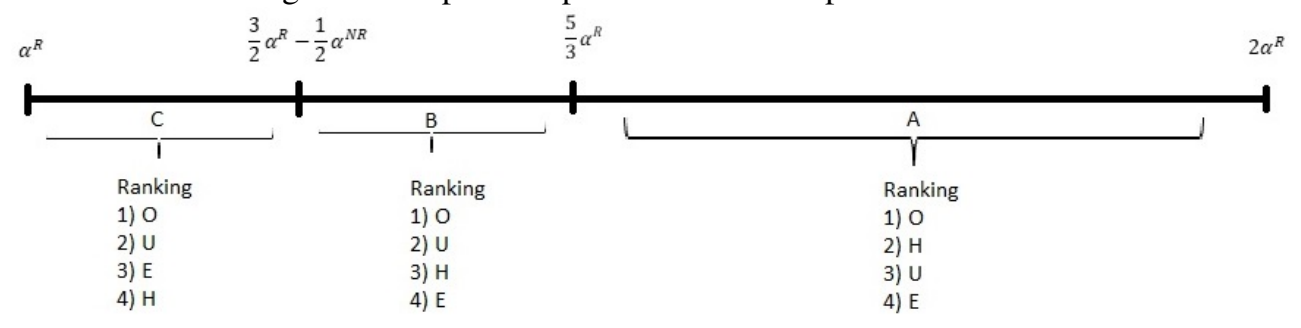

In the regime we propose both are at their maximum, because the immunity recipient is given full protection, as it is kept immune also on civil grounds, and the betrayed firm obtains the worst possible payoff, as it fails. Note that, in the parameters' space we examine, both outcomes do not depend on the information made available to the claimants.

In the Hungarian regime the loss of the non-reporting firm is the highest possible. This is obtained by giving the claimants access to the information provided by the leniency applicant. However, this choice negatively affects the protection granted to the first leniency applicant. Indeed, since the reporting firm has liability of last resort, its protection progressively diminishes as the available assets of the other cartelist become lower and its exposure in the civil action increases if the claimants can access the evidence submitted to the CA.

In the EU, the only form of protection given to the reporting firm stems from the impossibility of using the leniency documents. However, this form of protection also softens the loss suffered by the non-reporting firm, which, indeed, does not fail.

Finally in the US, the policy choice concerning the access to information increases the loss of the non-reporting firm. However, the protection of the amnesty recipient 
is limited as it only stems from the detrebling of damages and the fact that the reporting firm is responsible only for its direct damages. As a consequence the loss of the non-reporting firm may not reach its maximum value.

The issue with the existing regimes, (i.e. all but ours), is that the two policy instruments have opposite effects on the two factors that determine the degree of deterrence and this prevents the achievement of an optimal result. The analysis we have performed shows that it would be preferable to separate the two effects using the two available policy instruments. Our proposal does precisely this. The only way of obtaining this separation is to grant full immunity to the first reporting firm. When this is done, the other policy instrument can be used to maximize the loss suffered by the non-reporting firm without impairing the protection of the immunity recipient.

The critical discount factor in the regime we propose is:

$$
\delta^{*}(O)=1-\frac{\Pi-\rho\left(F+\alpha^{N R} D\right)}{\frac{1}{2} W}
$$

and this is the maximum discount factor that can be achieved if $\gamma \epsilon\left[\alpha^{R}, 2 \alpha^{R}\right)$.

In Appendix 8.5 we take up the formal analysis of the remaining cases and show that our conclusion remains valid. The intuitive explanation is simple. If firms' assets are very low, then in all legal regimes, but ours, the LP may become completely ineffective, because a firm that applies for leniency faces damages that may be larger than its available assets and this makes reporting irrational. Indeed, we have that the LP is ineffective in the Hungarian regime if $\gamma<\alpha^{R}$, in the EU if $\gamma<\alpha^{N R}$ and in the US if $\gamma<\frac{\alpha^{R}}{3}$, whereas in our regime, independently of the firm's assets, reporting is always the best course of action if a firm decides to play the non-collusive equilibrium. Since deterrence is stronger when a LP is effective, we have that the rules we propose remain those that guarantee the highest level of deterrence. 


\section{Litigation costs and deterrence vs compensation}

In this section, we study how our previous results change when we take into account litigation costs and the possibility that the immunity recipient could be the preferred target of damage actions. We then discuss the possible trade-off between deterrence and victims' compensation.

\subsection{Litigation costs}

The previous sections did not consider litigation costs and the possible incentives of cartel victims to target a specific cartel member in the action for damages. For simplicity we explore this extension only in the case of no bankruptcy. Let $T$ denote the litigation costs including those that derive from being the preferred target of the action for damages. 27

If neither or both firms apply for leniency, this cost is equally divided between the cartel members $\left(\frac{T}{2}\right)$. This holds also in the EU legal regime. ${ }^{28}$

In our solution, the immunity recipient has no liability for damages and the nonreporting firm(s) become(s) the preferred target, supporting the full cost $(T)$.

It can be shown that the difference between the discount factor thresholds of the EU and our proposed scenario is increasing in $T$, which implies the following.

Proposition 4: Taking into account the litigation cost and the possibility of being the preferred target of damage claims further increases the loss of deterrence implied by the EU solution relative to our proposed policy.

Proof in Appendix 8.6.

\footnotetext{
${ }^{27}$ With joint liability, this cost includes the financial costs of having to pay all the due damages first, and then the legal cost from recovering part of the damages paid from other cartel members.

${ }^{28}$ This is because in the EU there is no difference in liability (given that $D^{R}=D^{N R}$ ), nor an informational advantage in suing the immunity recipient (given that $\alpha^{R}=\alpha^{N R}$ ). On the other hand, although the leniency application is not accessible, there may be other reasons to target the immunity recipient, such as if he is declared guilty before the action for damages and does not appeal this decision.
} 


\subsection{Deterrence vs. compensation}

In this section we consider the potential trade-off between deterrence and compensation, at the center of the legal debate, and we discuss which solution is likely to be optimal once this is taken into account.

In the presence of potential bankruptcy, the maximum value of liquidated damages available to compensate victims of a non-deterred cartel (detected through an immunity application) is different from that in section 4 . With regard to the legal choices of liability of the immunity recipient and the amount of information available for damage actions, we can then state the following:

Lemma 1: If firms may be unable to compensate the victims of cartels uncovered due to leniency without the contribution of the immunity recipient and the LP remains effective in all legal regimes (i.e $\alpha^{R}<\gamma<2 \alpha^{R}$ ), these victims may be worse off under our proposed solution than under the US, EU and Hungarian solutions, while the latter maximizes victim's compensation.

Proof in Appendix 8.7.

We proceed by taking a closer look at this trade-off. We will identify the conditions that must be satisfied to make our proposal preferable to the Hungarian solution and will argue that those conditions are likely to hold in the real world.

We restrict our attention to customers' welfare and leave aside any allocative efficiency considerations that would strongly suggest focusing only on the deterrence properties of the enforcement system. Let us assume that all cartels (actual and potential) cause the same level of harm. Without any loss of generality we normalize to 1 the overall harm that would be caused by all potential cartels to both direct and indirect purchasers.

We define the "uncompensated harm", $U$, as the harm that is caused by those car- 
tels that are not deterred and for which the actual victims are not compensated. After all, if consumers were perfectly compensated, consumer welfare would be unaffected by cartels and if all cartels were all deterred consumer welfare would not depend on the outcome of a damage suit. The level of uncompensated harm depends (also) on the rules discussed in this paper. Hence, we can argue that one regime is better than another if the uncompensated harm is lower. We limit our comparison to the Hungarian regime and our proposal as the former maximizes actual compensation and the latter maximizes deterrence. The analysis can be easily extended to the other cases. As before, this comparison refers only to the legal choices regarding the liability of the immunity recipient and the amount of information available for subsequent actions for damages.

Let us denote by $U_{O}$ and $U_{H}$ the uncompensated harm that cartels cause if our solution or the Hungarian regime are adopted, respectively. Victims of cartels uncovered ex-officio by a CA receive the same amount of compensation in both regimes. Therefore, in this analysis, we assume that cartels' detection occurs only through the LP.

The uncompensated harm under ours and the Hungarian regimes is, respectively,

$$
U_{O}=\left[1-G\left(\delta_{O}\right)\right](1-\alpha \beta \lambda) \text { and } U_{H}=\left[1-G\left(\delta_{H}\right)\right](1-\alpha \beta),
$$

where $\delta_{O}$ and $\delta_{H}$ are the critical discount factors for cartel stability under each regime; $G(\delta)$ is the c.d.f. of the discount factor, which represents the fraction of deterred cartels in each regime; $\alpha$ is the share of the harm suffered by the undeterred cartels' victims that is compensated; $\beta$ is the share of undeterred cartels which are detected due to the LP and $\lambda$ is the share of awarded damages covered by the cartelists other than the immunity recipient. ${ }^{29}$

We have assumed that if all cartelists are kept liable they will be able to pay the total

\footnotetext{
${ }^{29} \mathrm{We}$ assume that, for some unmodeled reason, some cartel members still apply for leniency. This is because the formal model would imply that $\beta$ is zero as either a cartel is deterred, as potential cartelists anticipate that the LP would make it unstable, or if formed none of the cartelists report it. This would make our analysis trivial: the LP would only matter for its effects on deterrence.
} 
damages awarded by the court. ${ }^{30}$ For the sake of exposition, we write $G_{O}=G\left(\delta_{O}\right)$ and $G_{H}=G\left(\delta_{H}\right)$. Since deterrence is increasing in $\alpha^{R}$ and $\alpha_{O}^{R}=1 \geq \alpha R_{H}$ (as demonstrated before), then we have that $G_{O}>G_{H}$. The other parameters all are in the interval $[0,1] . .^{31}$

Our solution outperforms the Hungarian one if $U_{O}<U_{H}$. This condition can be rewritten as

$$
\left(G_{O}-G_{H}\right)(1-\alpha \beta \lambda)>\alpha \beta\left(1-G_{H}\right)(1-\lambda)
$$

The left-hand side of the inequality represents the benefit of our solution, which is given by the harm that would have been caused by the deterred cartels that would not be deterred under the Hungarian solution $\left(G_{O}-G_{H}\right)$, to the extent that this harm is not compensated in the successive actions for damages $(1-\alpha \beta \lambda)$.

The right-hand side represents the cost of our solution, which is given by the share of awarded damages, caused by the undeterred cartels in the Hungarian regime $\alpha \beta\left(1-G_{H}\right)$, which remains uncompensated precisely because the immunity recipient is kept immune from any civil liability $(1-\lambda){ }^{32}$ Simple manipulation of condition (3) leads to the following:

Proposition 5: The uncompensated cartel harm in the legal regime we propose is smaller than the uncompensated harm in the Hungarian regime if the following condition holds:

$$
1-\lambda<\frac{1-\alpha \beta}{\alpha \beta} \frac{G_{O}-G_{H}}{1-G_{O}}
$$

Although there are no general theoretical arguments that prove that the inequality

\footnotetext{
${ }^{30}$ This does not cause any loss of generality. Indeed, the possibility that some cartelists are unable to pay awarded damages in full even if the immunity recipient is kept liable can be accounted for by adjusting $\alpha$ accordingly.

${ }^{31}$ As mentioned earlier, although there are treble damages in the US, implying that $\alpha$ can take a value up to 3, Lande (1993) argues that US claimants are able to recover only a fraction of their actual losses.

${ }^{32}$ Condition (3) has a more general applicability: it can be used to assess any policy that improves deterrence while limiting the ability of the victims of actual cartels to be compensated. In this general case $G_{O}-G_{H}$ represents the positive impact on deterrence of the policy under exam, and $1-\lambda$ the negative impact on the victim's possibility of obtaining full compensation.
} 
in Proposition 4 always holds, identifying the exact condition that would make the legal regime we propose superior to the other regimes also in terms of "uncompensated harm" is useful as one can investigate if, as a matter of fact and in the real world, this condition is likely to be satisfied. Ultimately this is an empirical question that we do not address in this paper. However, by inspecting this condition one can understand that the result depends on the proportion of actual damages that are effectively redeemed in civil actions and on the extent to which cartel members other than the immunity recipient can pay awarded damages.

We believe that there are good reasons to believe that the former is sufficiently low and/ or the latter sufficiently high so that our solution performs better that the Hungarian one. In Appendix 8.8 we provide a more detailed discussion of the reasons behind this statement. In a nutshell they are: (1) the bankruptcy risk is likely to be low as we are not aware of any EU or US cases where awarded antitrust damages have led to the bankruptcy of a defendant; (2) the share of recovered damages is likely to be rather small since damage repayments are uncertain, lengthy and only some affected parties claim them; (3) empirical evidence suggests that the rate of cartel detection is likely to be low; and (4) if the immunity recipient is granted immunity also on civil grounds, the LP may become a more powerful deterrence mechanism.

\section{Conclusion}

Does the pursuit of the primary goal of the public enforcement system, i.e. achieving an optimal level of deterrence of anti-competitive conducts, necessarily require the amount of damages that claimants can expect to recover to be sacrificed?

The position of the ECJ summarized in Section 2 has the merit of clarifying that actions for damages initiated by the victims of an antitrust infringement may increase the level of deterrence. In this respect, public and private enforcement are not in conflict with each other. However, as far as hardcore cartels are concerned, the public interest 
has been pursued in many jurisdictions through the adoption of LPs. The legal debate has been centered on the question of whether damage actions can jeopardize the effectiveness of these programs.

In our view, many in this legal debate have incorrectly taken for granted that an inherent conflict exists between the proper functioning of a LP and private damage claims, so that any proper legislation necessarily implies a compromise between the interest of the public enforcement system and the interest of private cartel victims to be fully compensated. The EU Directive on damage actions follows this path. Our analysis shows that a compromise is not actually needed: one does not have to limit the ability of cartel victims to recover their losses to preserve the effectiveness of a LP. In fact, damage actions can even improve the effectiveness of such programs, through a legal regime in which the civil liability of the immunity recipient is minimized, while the other cartelists are jointly and severally liable toward all cartel's victims, and full access to all evidence collected by the competition authority, is granted to claimants.

The theoretical model discussed in the previous sections shows that the optimal solution is to limit as far as possible the damage liability of the immunity recipient.

The EU Directive limits this liability only marginally, but it also limits the information that is available to the claimants. These two instruments (lower liability of the immunity recipient and restriction of the available information) have different effects on deterrence and on the victims' ability to be fully compensated. Indeed, given that all cartelists are jointly and severally liable towards all of the cartel's victims, reducing the level of liability of the immunity recipient does not typically affect the amount of damages they can obtain. In contrast, limiting the evidence they can use in the damage actions reduces the expected value of the final compensation.

To give concrete application to the legal principle that any victim has the right to be fully compensated, the optimal solution, i.e. our proposal, is to grant complete access to all documents submitted by the immunity applicant and restrict (possibly eliminate) 
the civil liability of the immunity recipient. The resolution of restricting access to the information that is available in the Commission's file emerges as sub-optimal and might be considered at odds with the right of victims to obtain full compensation as recognized by the European courts.

In the analysis we assumed that only the first applicant can receive immunity from fines. As noted earlier, restricting access to LP statements and settlement submissions may be even more troublesome in the increasing number of cases in which the EC awards some degree of leniency to - and then settles with - most or all the members of a cartel (Marvão \& Spagnolo (2018b)). Then, the final decision will be informationally very poor, making leniency and settlements highly attractive but private actions much more difficult.

The US legislation is also sub-optimal because it only detrebles damages for the successful immunity recipient who, therefore, remains liable for single damages. The solution adopted in Hungary, before the Directive, was instead optimal when there is no risk of bankruptcy.

We have also considered the case in which firms may go bankrupt and therefore claimants cannot recover the entire awarded damages if the immunity recipient is not liable. Our analysis shows that also in this scenario our proposal remains optimal if deterrence is pursued. However, a conflict between deterrence and the victims' right to compensation may exist in this case. The Hungarian solution allows to maximize actual compensation and is still preferable to the EU and US regimes in terms of deterrence if firms' assets are not too low.

Finally, we have argued that the trade-off between deterrence and the right to compensation can be interpreted as a trade-off between the welfare of customers of potential but deterred cartels, and the welfare of customers of actual cartels then reported by one of the conspirators. On this basis, we have put forward arguments that support our conjecture that our proposal would entail a cost, in terms of risk of reduced compensation 
of actual victims, largely outweighed by its benefit, which is the full "compensation" of customers of potential cartels that are never damaged as the cartels are effectively deterred.

A final note is warranted. Cartel detection may occur also through channels other than the LP. Cartels victims may report their suspicions to a competition authority and trigger an investigation. They may have an incentive to do so also by the prospect of recovering damages, once the infringement has been proved. Limiting cartel members' liability and access to information would reduce the incentive to search for signs of cartels. We do not discuss this detection mechanism in our paper as we focus on rules that apply when the cartel is discovered through a leniency applicant's report. If the cartel is discovered through a different channel these rules do not affect in any way cartel members' liability and the information that claimant can use in the following action for damages and, therefore, they do not alter the incentives for customers to search for cartels that did not self-report.

The issue may become relevant only when leniency is given also to firms after the cartel is discovered by a customers' complaint. In that case, our position is that the leniency applicant should not be given full immunity, nor protection from civil liability and that the information provided by the leniency applicant should be made available to the claimant in follow-on civil actions. Fully exploring the implications of this proposal, however, would require a completely novel paper. 


\section{Appendix}

\subsection{Proof of Proposition 1}

In this proof we treat $l_{L}$ and $\alpha_{L}^{R}$ as continuous variables. Since the fraction of industries in which cartels are sustainable in equilibrium is decreasing in $\underline{\delta}$, cartel deterrence is higher for a higher $\underline{\delta}$. Taking the derivative of $\underline{\delta}$ with respect to the share of damages which the immunity recipient is expected to pay $\left(l_{L} \alpha_{L}^{R}\right)$ yields

$$
\frac{\partial \underline{\delta}}{\partial\left(l_{L} \alpha_{L}^{R}\right)}=-D \frac{\Pi-\rho\left(F+\alpha^{N R} D\right)}{\left(2 \Pi-l_{L} \alpha_{L}^{R} D\right)^{2}}
$$

which is strictly negative. Since $l_{L} \alpha_{L}^{R} \geq 0$, this implies that $\underline{\delta}$, hence cartel deterrence, reaches a maximum at the corner $l_{L} \alpha_{L}^{R}=0$. Since we assumed $\alpha^{R} \geq \alpha^{N R}>0$, setting $l_{L} \alpha_{L}^{R}=0$ necessarily requires $l_{L}=0$, which is only the case under our proposal and under the current assumption of no risk of bankruptcy - in the Hungarian legal regime. The proposition statement follows.

\subsection{Empirical evidence on strategic risk}

In this section, we provide suggestive evidence on the importance of distrust/ strategic risk concerns in cartels by presenting transcripts from public reports on cartels convicted by the European Commission. These show that distrust between cartel members is a serious issue for cartel partners. In fact, we also report some examples where the risk of a specific cartel member abandoning the collusive agreement is accurately anticipated and evaluated.

\subsubsection{Examples of distrust from a specific cartel member who reports the cartel}

1. Retail food packaging $(2015)^{33}$

\footnotetext{
${ }^{33} \mathrm{EC}$, Decision of 24.6.2015, case AT.39563, par 241 and 270.
} 
- "This tense situation is also reflected in an internal Coopbox report of 27 June 2005 concerning the situation of the market and relations with cartel participants, which states that "today there are no conditions to find an agreement with Linpac (...) it is not trustworthy". (...) Finally the cartel participants discussed possible strategies on how to protect their plan against Magic Pack, who was not to be trusted."

- Linpac was the first cartel member to report the cartel and receive immunity from fines.

2. Fine art auction houses $(2002)^{34}$

- "There were also fears that Christie's would not adhere to the agreed commission structure."

- In fact, Christies was the first firm to report the cartel and receive immunity from fines.

\subsubsection{Examples of distrust from a specific cartel member}

1. Smart card chips $(2014)^{35}$

- "[...] especially in 2004 competitors feared that Samsung would drive pricing down with its aggressive pricing policy based on its better cost structure (...) [...]'s understanding was that [...] no longer trusted Atmel after their loss of the Gemplus tender mentioned in recital (120), and wanted to secure share at Axalto by accepting Axalto's aggressive target price."

2. Prestressing Steel (2010)

\footnotetext{
${ }^{34}$ EC, Decision of 30.10.2002, case COMP/E-2/37.784, par 113.

${ }^{35} \mathrm{EC}$, Decision of 3.9.2014, case AT.39574, par 121 and 124.
} 
- "At the meeting held in Malpensa on 04.09.2001 (see recital (285)), the Italian producers present agreed to meet to fix the sales prices in Europe. The typed minutes from SLM state that Tycsa's absence raised fears."

\subsubsection{Examples of distrust between cartel members}

1. Retail food packaging (2015)

- "The intensity and frequency of the meetings shows that the cartel participants did not fully trust each other at that time."

2. Sorbates (2003)

- "There was some distrust among the producers concerning the implementation of target prices and volume quotas. The participants knew that sales figures were often understated. At the autumn joint meeting, Hoechst and the Japanese producers compared sales results to date for the current calendar year with the volume quotas established at the spring joint meeting so that they could monitor compliance with the market allocations."

- Note that Hoechst was the second leniency reporter (50\% fine reduction).

3. Vitamins (2001)

- "According to Roche the significant degree of distrust prevailing between the participants prevented their agreeing a mechanism for fixing target quantities for consecutive quarterly and half-yearly periods. Tanabe confirms that the participants did not agree on a mechanism for fixing target quantities on an ongoing basis. Merck however says that on the basis of Roche's forecast of the expected market for 1992, the sales volumes of each producer were in fact agreed. This is confirmed by the documentary evidence." 
- Note that the first reporter was Rhone-Poulenc but Roche was the first reporter in subsequent cartel reports within this case (vitamins B2, B5, C and D3).

\subsection{Discussion of strategic risk and derivation of the critical dis- count factor $\delta^{*}$}

In this Appendix, using a very simple example, we explain why risk considerations are likely to determine the equilibrium selection in a coordination game and derive the condition (1) that captures how deterrence works through strategic risk.

Consider the following game:

Table 1: Game matrix (1)
\begin{tabular}{|c||c|c|}
\hline & $C_{2}$ & $R_{2}$ \\
\hline \hline$C_{1}$ & $\mathrm{~A}, \mathrm{a}$ & $\mathrm{D}, \mathrm{b}$ \\
$R_{1}$ & $\mathrm{~B}, \mathrm{~d}$ & $\mathrm{C}, \mathrm{c}$ \\
\hline
\end{tabular}

in which $A>B>C>D$ for player 1 and $a>b>c>d$ for player 2. This game has two Nash equilibria in pure strategies: $\left(C_{1}, C_{2}\right)$ and $\left(R_{1}, R_{2}\right)$. The former Pareto dominates the latter: both players are better off if they select this equilibrium. However, this may not be enough to lead to this outcome as $\left(C_{1}, C_{2}\right)$ might be riskier than $\left(R_{1}\right.$, $R_{2}$ ). To grasp this concept, suppose that player 1 is uncertain about the strategy that 2 will play and attaches the same probability, 0.5 , to both. The less risky strategy for player 1, given her ignorance, is the one that maximizes her expected payoff. For instance, $R_{1}$ is less risky than $C_{1}$ if $0.5 A+0.5 D<0.5 B+0.5 C$. The strategy profile $\left(R_{1}\right.$, $R_{2}$ ) is risk dominant if the two strategies are the least risky for both players (Harsanyi \& Selten, 1988). Suppose that indeed $\left(R_{1}, R_{2}\right)$ is risk dominant. This implies that the two following conditions hold:

$$
A+D<B+C \text { and } a+d<b+c,
$$

which can be rewritten as: 


$$
D-C<B-A \text { and } d-c<b-a \text {. }
$$

Note that $(D-C)$ is the loss player 1 suffers if she deviates from the equilibrium $\left(R_{1}, R_{2}\right)$ and $(B-A)$ is the loss for deviating from the equilibrium $\left(C_{1}, C_{2}\right)$ : Similarly, for $(d-c)$ and $(b-a)$. This means that all these terms are negative by definition. Therefore, we can summarize the two conditions that make $\left(R_{1}, R_{2}\right)$ risk dominant in the following simpler condition as defined by Harsanyi \& Selten (1988):

$$
(D-C)(d-c)>(B-A)(b-a) \text {. }
$$

The term $(D-C)(d-c)$ is called the Nash product of the pair of strategies $\left(R_{1}, R_{2}\right)$ and $(B-A)(b-a)$ is the Nash product of $\left(C_{1}, C_{2}\right)$. If the game is symmetric (i.e. $A=a$, $B=b, C=c$ and $D=d)$ the Nash products are $(D-C)^{2}$ and $(B-A)^{2}$ and the above condition becomes:

$$
(D-C)^{2}>(B-A)^{2},
$$

which is equivalent to $|D-C|>|B-A|$, and since $C>D$ and $A>B$, becomes:

$$
(C-D)>(A-B)
$$

In the following we will use this condition to identify the risk dominant strategy. If the game is symmetric and this condition is satisfied, then the outcome of the game is $\left(R_{1}, R_{2}\right)$ if players' decisions are led by risk considerations, even if $\left(C_{1}, C_{2}\right)$ Pareto dominates $\left(R_{1}, R_{2}\right)$.

The reader may wonder why risk considerations should matter in the case of explicit collusion where players agree to play the more profitable equilibrium. To understand this, one has to consider that the collusive agreement is just a pre-play communication in which each player reassures the other that she will choose the collusive strategy. However, this reassurance may not be really able to affect the other player's expectation. Consider Table 1 again. Player 2 in any case is better off if 1 plays $C_{1}(a>d$ and $b>c$ ). So, she should try to convince player 1 to play $C_{1}$. The only way to do 
so is to reassure 1 that she will play $C_{2}$, because only if 2 plays $C_{2}$ it is in the best interest of 1 to play $C_{1}$. Therefore, the reassurance has very little value, as 1 knows that 2 would make it even if in fact she plans to play $R_{2}$, so that, in the end it works only if player 1 trusts player 2 . The deterrence effect we are interested in hinges on the possibility of impairing this trust. By luring cartel members to report with the promise of a very favorable treatment, a legal regime may reduce the level of trust firms have in each other. This in turn has a stronger deterrence effect the riskier is for the two players the decision to incorrectly trust the other, i.e. the stronger the "strategic risk". The relevance of trust in real life cartels has been documented in Appendix 8.2. Moreover, the experimental evidence cited in the paper shows that strategic risk is an important deterrence channel.

Now we can turn to the analysis of a repeated interaction. Following Spagnolo (2004), Blonski et al. (2011) and Blonski \& Spagnolo (2015), we can simply build a $2 \times 2$ game matrix where the payoff associated to any strategy profile is given by the expected discounted payoff of the continuation game, as in Table 2.

Table 2: Game matrix (2)

\begin{tabular}{|c||c|c|}
\hline & $C_{j}$ & $R_{j}$ \\
\hline \hline$C_{i}$ & $V^{N R}, V^{N R}$ & $V^{O R}, V^{R}$ \\
$R_{i}$ & $V^{R}, V^{O R}$ & $V^{B R}, V^{B R}$ \\
\hline
\end{tabular}

In this matrix $V^{R}$ is the expected discounted payoff of a firm that plays the noncollusive equilibrium and reports the cartel to the CA while the opponent plays the collusive equilibrium, $V^{B R}$ is the expected discounted payoff of a firm when both firms play the non-collusive equilibrium and report the cartel to the CA and $V^{O R}$ is the expected discounted payoff of the betrayed firm that plays the collusive equilibrium while the opponent switches to the non-collusive equilibrium and reports the cartel to the CA. Hence, we have: 


$$
\begin{gathered}
V^{N R}=\frac{\Pi-\rho\left(F+\alpha^{N R} D\right)}{1-\delta}, \\
V^{R}=-l_{L} \alpha_{L}^{R} D, \\
V^{B R}=-\frac{-F-\left(1+l_{L}\right) \alpha_{L}^{R} D}{2}, \\
V^{O R}=-F-\alpha_{L}^{R} D .
\end{gathered}
$$

In all legal regimes we have that $V^{N R}>V^{R}>V^{B R}>V^{O R}$. Hence, game matrix (2) has the same payoff ranking as game matrix (1). Thus, we can directly apply the results described above and state that the collusive equilibrium risk dominates the reporting equilibrium if:

$$
V^{N R}-V^{R} \geq V^{B R}-V^{O R}
$$

From condition (5) we can derive the critical discount factor $\delta^{*}$ which takes into account strategic risk:

$$
\delta \geq \delta^{*}(L) \equiv 1-\frac{\Pi-\rho\left(F+\alpha^{N R} D\right)}{\frac{F}{2}+\left(1-2 l_{L}\right) \alpha_{L}^{R} D},
$$

which is condition 1 reported in the paper, in section 4.2. This discount factor $\delta^{*}$ reflects the riskiness to cooperate.

Since $V^{B R}=\frac{1}{2}\left(V^{O R}+V^{R}\right), \delta^{*}$ can also be expressed as:

$$
\delta^{*}(L)=1-\frac{V^{N R^{\prime}}}{\frac{3 V^{R}-V^{O R}}{2}},
$$

where $V^{N R \prime}$ is the numerator of $V^{N R}$. 


\subsection{Proof of Proposition 2}

In this proof we treat $\alpha_{L}^{R}$ as a continuous variable in the interval $\left[\alpha^{N R}, 1\right]$ and $l_{L}$ as a continuous variable in the interval $[0,2)$.

Differentiating $\delta^{*}$ with respect to $l_{L}$ yields

$$
\frac{\partial \delta^{*}}{\partial l_{L}}=-2 D \alpha_{L}^{R} \frac{\Pi-\rho\left(F+\alpha^{N R} D\right)}{\left[\frac{F}{2}+\alpha_{L}^{R} D\left(1-2 l_{L}\right)\right]^{2}},
$$

which is strictly negative.

Differentiating $\delta^{*}$ with respect to $\alpha_{L}^{R}$ yields

$$
\frac{\partial \delta^{*}}{\partial \alpha_{L}^{R}}=\left(1-2 l_{L}\right) D \frac{\Pi-\rho\left(F+\alpha^{N R} D\right)}{\left[\frac{F}{2}+\alpha_{L}^{R} D\left(1-2 l_{L}\right)\right]^{2}},
$$

which is strictly positive if $l_{L}<\frac{1}{2}$ and strictly negative if $l_{L}>\frac{1}{2}$.

Proposition 2c) is implied by Proposition 2a) and 2b). A more direct proof is obtained by comparing the critical discount factor in the two regimes $O$ and $H$ with the critical values in the other two regimes. The former is

$$
\delta^{*}(O)=\delta^{*}(H)=1-\frac{\Pi-\rho\left(F+\alpha^{N R} D\right)}{\frac{F}{2}+\alpha^{R} D},
$$

while we have

$$
\delta^{*}(E)=1-\frac{\Pi-\rho\left(F+\alpha^{N R} D\right)}{\frac{F}{2}-\alpha^{N R} D},
$$

and

$$
\delta^{*}(U)=1-\frac{\Pi-\rho\left(F+\alpha^{N R} D\right)}{\frac{F}{2}+\frac{1}{3} \alpha^{R} D} .
$$

It is immediate to see that $\delta^{*}(O)=\delta^{*}(H)>\delta^{*}(U)>\delta^{*}(E)$ as $\alpha^{R}>\frac{1}{3} \alpha^{R}>-\alpha^{N R}$. 


\subsection{Robustness check with bankruptcy}

In this appendix we complete the proof of Proposition 3 and discuss the remaining cases.

\section{Proof of Proposition 3}

If $\alpha^{R} \leq \gamma<2 \alpha^{R}$ the critical discount that takes into account strategic risk in the different regimes is described by the following equations.

$$
\begin{gathered}
\delta^{*}(O)=1-\frac{\Pi-\rho\left(F+\alpha^{N R} D\right)}{\frac{1}{2} W} \\
\delta^{*}(H)=1-\frac{\Pi-\rho\left(F+\alpha^{N R} D\right)}{-\frac{3}{2} F+2 W-3 \alpha^{R} D} \\
\delta^{*}(E)=1-\frac{\Pi-\rho\left(F+\alpha^{N R} D\right)}{\frac{1}{2} F-\alpha^{N R} D} \\
\delta^{*}(U)=\left\{\begin{array}{ll}
1-\frac{\Pi-\rho\left(F+\alpha^{N R} D\right)}{\frac{1}{2} F+\frac{1}{3} \alpha^{R} D} & \text { if } \gamma \geq \frac{5}{3} \alpha^{R} \\
1-\frac{\Pi-\rho\left(F+\alpha^{N R} D\right)}{\frac{1}{2} W-\frac{1}{2} \alpha^{R} D} & \text { if } \gamma<\frac{5}{3} \alpha^{R}
\end{array} .\right.
\end{gathered}
$$

Comparing the critical discount factor in our solution with that arising in the other cases, we find that $\delta^{*}(O)>\delta^{*}(E)$ iff $W>F-2 \alpha^{N R} D ; \delta^{*}(O)>\delta^{*}(H)$ iff $\gamma<2 \alpha^{R}$; when $\gamma \geq \frac{5}{3} \alpha^{R}, \delta^{*}(O)>\delta^{*}(U)$ iff $\gamma \geq \frac{2}{3} \alpha^{R}$, and when $\gamma<\frac{5}{3} \alpha^{R}, \delta^{*}(O)>\delta^{*}(U)$ iff $\frac{\alpha^{R}}{2} D>0$. All the necessary and sufficient conditions just identified are always satisfied given the admissible values of the relevant parameters. This proves Proposition $3 a$ ).

Note that the critical discount factor with strategic risk in our regime, $\delta^{*}(O)$, is (weakly) higher than the critical discount factor stemming from the ICC in the same regime, $\underline{\delta}(O)$, iff $\frac{W}{2} \geq 2 \Pi$. This is always satisfied under the assumption that the fine is "meaningful" (i.e. $\frac{F}{2} \geq 2 \Pi$, see section 4.2) and since we have assumed that $W>F$. Note that the fine being "meaningful" is a sufficient but not necessary condition. 
We can now compare the US and the EU regimes. When $\gamma \geq \frac{5}{3} \alpha^{R}, \delta^{*}(U)>\delta^{*}(E)$ iff $\frac{1}{3} \alpha^{R}>-\alpha^{N R}$, and if $\gamma<\frac{5}{3} \alpha^{R}, \delta^{*}(U)>\delta^{*}(E)$ iff $\gamma>\alpha^{R}-2 \alpha^{N R}$. Again, these conditions always hold, which proves Proposition $3 b)$.

The comparison between the Hungarian solution and the US one reveals that for any $\alpha^{R} \leq \gamma<2 \alpha^{R}$, we find that $\delta^{*}(H)>\delta^{*}(U)$ iff $\gamma>\frac{5}{3} \alpha^{R}$; Proposition $3 c$ ) follows.

Finally, $\delta^{*}(H) \geq \delta^{*}(E)$ iff $\gamma \geq \frac{3}{2} \alpha^{R}-\frac{1}{2} \alpha^{N R}$ (Proposition $\left.3 d\right)$ ).

\section{Bankruptcy and $\gamma<\alpha^{R}$}

Here we briefly discuss the (rather unlikely) case that all cartelists' assets are insufficient to cover the awarded damages when claimants have access to the leniency documents, i.e. $\gamma<\alpha^{R}$.

Let's consider first the case in which $\rho F \geq \alpha^{N R} D(1-\rho)$ and $\rho F \geq D\left(\frac{\alpha^{R}}{3}-\rho \alpha^{N R}\right)$. These conditions guarantee that in the EU and in the US regimes a firm which deviates, also applies for leniency, if this does not provoke its bankruptcy. However, if $\gamma<\alpha^{R}$ depending on the legal regime we discuss, it might be that a firm that reports the cartel to the CA does not have sufficient assets to pay damages and fails. If this does not happen the analysis conducted in the previous section remains valid and shows that the critical discount factor in our regime is higher than the one arising in the other regimes. We therefore need to ascertain when the reporting firm goes bankrupt.

A firm goes bankrupt when $\gamma<\alpha^{R}$ in the Hungarian regime, $\gamma<\frac{1}{3} \alpha^{R}$ in the US regime and $\gamma<\alpha^{N R}$ in the EU. When one of these conditions is satisfied a deviating firm does not apply for leniency. Hence the LP is ineffective and the critical discount factor is the one that stems from the ICC without the LP: in particular if $\gamma \geq \alpha^{N R}$, we have

$$
\underline{\delta}_{N L}=1-\frac{\Pi-\rho\left(F+\alpha^{N R} D\right)}{2 \Pi-\rho\left(F+\alpha^{N R} D\right)} .
$$

In the regime we propose the firm that deviates finds it optimal to apply for leniency for any value of $\gamma$ and $\rho F$. The critical discount factor in our proposal stemming from 
the ICC is

$$
\underline{\delta}(O)=1-\frac{\Pi-\rho\left(F+\alpha^{N R} D\right)}{2 \Pi}
$$

and is apparently higher than $\underline{\delta}_{N L}$. Deterrence is obviously stronger if we consider strategic risk as $\delta^{*}(O)>\underline{\delta}(O)$ as discussed before.

When $\gamma<\alpha^{N R}$ if the firm is caught by an autonomous investigation of the CA, it fails and its wealth is 0 . Hence, the expected discounted value of colluding is

$$
V_{\gamma<\alpha^{N R}}^{N R}=\frac{\Pi-\rho W}{1-(1-\rho) \delta},
$$

and the critical discount factor becomes:

$$
\underline{\delta}_{\gamma<\alpha^{N R}}=\frac{1}{1-\rho}\left(1-\frac{\Pi-\rho W}{2 \Pi-l_{L} \alpha_{L}^{R} D}\right) .
$$

In the regime we propose the reporting firm never fails, while the non-reporting one always does. Moreover both firms fail if the cartel is uncovered by the CA. Therefore, the critical discount factor stemming from the ICC is

$$
\underline{\delta}(O)_{\gamma<\alpha^{N R}}=\frac{1}{1-\rho}\left(1-\frac{\Pi-\rho W}{2 \Pi}\right)
$$

and again is clearly higher than $\underline{\delta}_{\gamma<\alpha^{N R}}$. Moreover the critical discount factor in our regime if strategic risk is considered is:

$$
\delta^{*}(O)_{\gamma<\alpha^{N R}}=\frac{1}{1-\rho}\left(1-\frac{\Pi-\rho W}{\frac{W}{2}}\right),
$$

which shows that deterrence is even stronger in this case under the assumptions of the model. Hence, all our conclusions remain valid.

Finally, if $\rho F<\alpha^{N R} D(1-\rho)$ a firm that deviates in the EU regime does not apply for leniency, independently of the value of $\gamma$. Similarly in the US regime if $\rho F<$ 
$D\left(\frac{\alpha^{R}}{3}-\rho \alpha^{N R}\right)$. The critical discount factor is thus either expression (8) or expression (9) depending on the value of $\gamma$, while in our regime it is either expression (7) (if $\gamma \geq \alpha^{N R}$ ) or expression (10) (if $\gamma<\alpha^{N R}$ ). We can conclude that also in this case our solution outperforms the alternative regimes.

\subsection{Proof of Proposition 4}

Taking into account the cost of litigation and of being the preferred target of the damage action $(T)$, the new value functions become

$$
\begin{aligned}
& V^{N R}(T)=V^{N R}-\frac{\rho}{1-\delta} \frac{T}{2} ; \\
& V^{B R}(T)=V^{B R}-\frac{T}{2} ; \\
& V_{E}^{R}(T)=V^{R}-\frac{T}{2} ; V_{O}^{R}(T)=V^{R}-0 ; \\
& V_{E}^{O R}(T)=V^{O R}-\frac{T}{2} ; V_{O}^{O R}(T)=V^{O R}-T .
\end{aligned}
$$

Using equation (6), from subsection 8.3 , for $\delta^{*}$, the new discount factor thresholds are given by

$$
\begin{aligned}
& \delta_{E}^{*}(T) \equiv 1-\frac{V^{N R^{\prime}}-\rho \frac{T}{2}}{\left(V^{B R}-\frac{T}{2}\right)-\left(V^{O R}-\frac{T}{2}\right)+\left(V^{R}-\frac{T}{2}\right)}=1-\frac{V^{N R^{\prime}}-\rho \frac{T}{2}}{V^{B R}-V^{O R}+V^{R}-\frac{T}{2}} \\
& \delta_{O}^{*}(T) \equiv 1-\frac{V^{N R^{\prime}}-\rho \frac{T}{2}}{\left(V^{B R}-\frac{T}{2}\right)-\left(V^{O R}-T\right)+\left(V^{R}-0\right)}=1-\frac{V^{N R^{\prime}}-\rho \frac{T}{2}}{V^{B R}-V^{O R}+V^{R}+\frac{T}{2}} .
\end{aligned}
$$

The difference between the discount factor thresholds of ours and the EU solutions is the following

$$
\delta_{O}^{*}(T)-\delta_{E}^{*}(T)=\frac{V^{N R^{\prime}} T-\rho \frac{T^{2}}{2}}{\left(V^{B R}-V^{O R}+V^{R}\right)^{2}-\frac{T^{2}}{4}} .
$$


Differentiating this difference with respect to $T$ yields

$$
\frac{\partial\left[\delta_{O}^{*}(T)-\delta_{E}^{*}(T)\right]}{\partial T}=\frac{\left(V^{N R^{\prime}}-\rho T\right)\left(V^{B R}-V^{O R}+V^{R}\right)^{2}+\frac{T^{2}}{4} V^{N R^{\prime}}}{\left[\left(V^{B R}-V^{O R}+V^{R}\right)^{2}-\frac{T^{2}}{4}\right]^{2}},
$$

which is strictly positive.

\subsection{Proof of Lemma 1}

In our analysis, we focus on the legal choices of liability of the immunity recipient and the amount of information available for damage actions. This can be interpreted as if a jurisdiction (eg. the EU) would adopt the solution from another jurisdiction (eg. Hungary) in regards to the two policy variables $l_{L}$ and $\alpha_{L}^{R}$ only, rather than the entire legal regime.

If $\alpha^{R} \leq \gamma<2 \alpha^{R}$ actually compensated (paid) damages, denoted by $P(L)$, are: $P(O)=\gamma D ; P(H)=2 \alpha^{R} D ; P(E)=2 \alpha^{N R} D$ and $P(U)=\min \left\{2 \alpha^{R} D,\left(\frac{1}{3} \alpha^{R}+\gamma\right) D\right\}$. Hence we have that $P(O)<P(U) \leq P(H)$; further we have $P(E)<P(H)$; finally we have that $P(O) \leq P(E)$ iff $\gamma \leq 2 \alpha^{N R}$ and $P(E) \leq P(U)$ iff $\gamma \geq 2 \alpha^{N R}-\frac{1}{3} \alpha^{R}$. This is shown in figure 3.

This proves that, if the non-reporting firm does not have sufficient assets to pay damages in full, but this can be paid with the aggregated assets of all cartelists, the Hungarian regime guarantees the highest amount of actually compensated damages while our proposal leads to a value of compensated damages that is certainly lower than the one obtained in the Hungarian and in US regimes and may be lower than the one in the EU regime. 
Figure 3: Graphical representation of Lemma 1

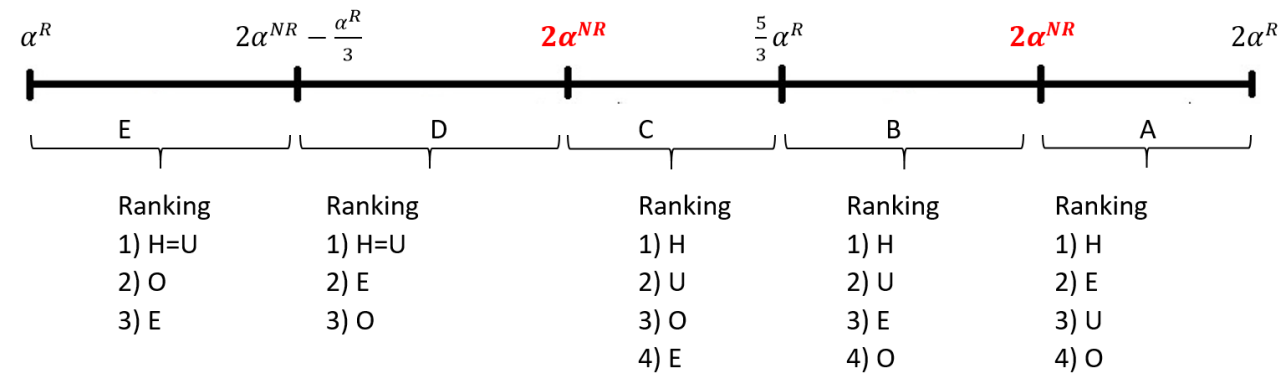

\subsection{Discussion on Deterrence vs. Compensation}

Below, we discuss some reasons to presume that the benefit of our proposal is likely to be larger than its cost.

(1) The bankruptcy risk. The left-hand side of condition (4) represents the extent to which keeping the immunity recipient liable is necessary to guarantee that awarded damages are fully paid. We are not aware of cases, either in the US or the EU, where a court's decision to award antitrust damages has caused the bankruptcy of a defendant (although this risk is often cited). Keeping in mind that all cartel members are already severally and jointly liable toward the cartel's victims, we believe that the rare (if any) occurrence of bankruptcy cases due to the award of antitrust damages suggests that $\lambda$ is likely to be close to 1 and, therefore, the left-hand side of condition (4) close to $0 .{ }^{36}$

(2) The share of recovered damages. We believe that $\alpha$ (i.e. the share of damages caused by the undeterred cartels' which is compensated) is quite low and we would not be surprised if an empirical analysis showed that its likely value is significantly below 0.5. The reason for this is threefold. Firstly, cartels do not only affect actual direct purchasers of the cartelized products but also other players along the value chain, both downstream and upstream, as well as potential customers of the cartelized products

\footnotetext{
${ }^{36}$ In our simple model, if $\lambda=1$ we have that $G_{O}=G_{H}$, so that the right-hand side of (4) is 0 . Yet, the model does not consider that, under the Hungarian solution, the immunity recipient is still likely to be involved in the trial, whereas in the legal regime we propose, it will be totally exonerated from any civil liability. If we consider this additional element, the cost that the trial would impose on the immunity recipient in the Hungarian regime would make the LP less attractive, therefore diminishing its deterrent effect.
} 
that are not served at the cartel price and potential customers of downstream products that are equally excluded from consumption as a consequence of the higher price. In principle, all these subjects could sue cartel members in order to recover the harm they suffered. ${ }^{37}$ In practice, suppliers and indirect purchasers very rarely do so and potential customers never do.

Secondly, damage repayment is uncertain and lengthy, and civil actions entail costs that are only partially reimbursed by the losing party. These costs include in-house counsels, executive and board of directors' time, and the distraction of employees' time and efforts from business activity.

Thirdly, frequently the statute of limitations impedes the recovery of damages occurred in the initial years of the violation and, in some cases, may immunize cartel members from any damage payout.

(3) The rate of cartel detection. Let us now consider the likely range of values for $\beta$, i.e. the rate of undeterred cartels which are detected through a leniency application. Theoretically, in a deterministic model this value is 0 . In fact, we observe some cases in which an application occurs before the start of an investigation by a CA. However, there is evidence that these are infrequent. Marx et al. (2015) estimate that 80-90\% of leniency applications received by the US DOJ happened after the DOJ launched an investigation, and Marvão (2015) reports that, in the EU, 51\% of the 377 leniency applications in the period of 1996-2014 were filed after an investigation was opened. ${ }^{38}$ Hence, the rate of detection, $\beta$, is also likely to be very low. Again, we think that it would be safe to predict that $\beta$ is below 0.5 .

(4) The rate of cartel deterrence. If the two above educated guesses of the true

\footnotetext{
${ }^{37}$ However, in the US, indirect purchasers do not have standing for infringements of federal antitrust law.

${ }^{38} \mathrm{~A}$ decision to apply for leniency, even if there is no sign that an ex-officio investigation may be opened in the near future, is often linked to an extraordinary event such as a merger or take-over, when the new owners/management become aware of the violations during the due diligence process and decide to "clear the table" of any previous misbehavior. Other pre-investigation leniency applications are due to a knock-on effect whereby the start of an investigation in one market triggers a leniency application in other markets where one or more of the firms involved in the first investigation operate. For example, in the period of 1996 to 2014, 20 of the 46 cartels reported to the European Commission, pre-investigation, were already being investigated in the US (see Marvão \& Spagnolo (2018b)) for more on "Leniency Inflation" in the EU.
} 
values of $\alpha$ and $\beta$ are correct, the odds of having the actual harm uncompensated $\left(\frac{1-\alpha \beta}{\alpha \beta}\right)$ is above 1 , which is the maximum (and implausible) value of the left-hand side term of condition (4). This does not suffice to conclude that this condition is satisfied, as the last term on the right-hand side may still be lower than 1. On this, we can only say that if the immunity recipient is granted immunity also on civil grounds, we suspect that the LP may become a powerful deterrence mechanism, so that the fraction of undeterred cartels $\left(1-G_{o}\right)$ is relatively low and there is an improvement in deterrence with respect to the Hungarian regime $\left(G_{o}-G_{H}\right)^{39}$, and even more so with respect to the other regimes currently in place.

${ }^{39}$ See footnote 35 . 


\section{References}

Aubert, Cécile, Kovacic, William, \& Rey, Patrick. 2006. The Impact of Leniency and Whistleblowing Programs on Cartels. International Journal of Industrial Organization, 24(6), 1241-1266.

Bernard, Kent. 2012. Making victims whole: A restitution approach to cartel damages. Competition Law Journal Concurrences, 1, 1-9.

Bigoni, Maria, Casari, Marco, Skrzypacz, Andrzej, \& Spagnolo, Giancarlo. 2015a. Time horizon and cooperation in continuous time. Econometrica, 83(2), 578-616.

Bigoni, Maria, Fridolfsson, Sven-Olof, Le Coq, Chloe, \& Spagnolo, Giancarlo. 2015b. Trust, Leniency and Deterrence. Journal of Law, Economics and Organizaton, 31(4), 663-689.

Blonski, Matthias, \& Spagnolo, Giancarlo. 2015. Prisoner's other Dilemma. International Journal of Game Theory, 44(1), 61-81.

Blonski, Matthias, Ockenfels, Peter, \& Spagnolo, Giancarlo. 2011. Equilibrium Selection in the Repeated Prisoner's Dilemma: Axiomatic Approach and Experimental Evidence. American Economic Journal: Microeconomics, 3(3), 164-192.

Bourjade, Sylvain, Rey, Patrick, \& Seabright, Paul. 2009. Private Antitrust Enforcement in the Presence of Pre-Trial Bargaining. The Journal of Industrial Economics, 57(3), 372-409.

Breitmoser, Yves. 2015. Cooperation, but no Reciprocity: Individual Strategies in the Repeated Prisoner's Dilemma. American Economic Review, 105(9), 2882-2910.

Buccirossi, Paolo. 2008. FFacilitating Practices. Pages 305-351 of: Buccirossi, Paolo (ed), Handbook of Antitrust Economics, Chapter 8. The MIT Press, Cambridge. 
Buccirossi, Paolo, \& Spagnolo, Giancarlo. 2006. Leniency policies and illegal transactions. Journal of Public Economics, 90(6-7), 1281-1297.

Buccirossi, Paolo, Ciari, Lorenzo, Duso, Tomaso, Spagnolo, Giancarlo, \& Vitale, Cristiana. 2013. Competition Policy and Productivity Growth: An Empirical Assessment. Review of Economics and Statistics, 4(95), 1324-1336.

Calford, Evan, \& Oprea, Ryan. 2017. Continuity, Inertia, and Strategic Uncertainty: A Test of the Theory of Continuous Time Games. Econometrica, 85(3), 915-935.

Cauffman, Caroline. 2011. The Interaction of Leniency Programmes and Actions for Damages. The Competition Law Review, 7(2), 181-220.

Chen, Zhijun, \& Rey, Patrick. 2013. On the Design of Leniency Programs. The Journal of Law and Economics, 56(4), 917-957.

Dal Bó, Pedro, \& Fréchette, Guillaume. 2011. The Evolution of Cooperation in Infinitely Repeated Games: Experimental Evidence. American Economic Review, 101(1), 411-429.

Dal Bó, Pedro, \& Fréchette, Guillaume. 2018. On the Determinants of Cooperation in Infinitely Repeated Games: A Survey. Journal of Economic Literature, 56(1), $60-114$.

Embrey, Matthew, Fréchette, Guillaume, \& Yuksel, Sevgi. 2018. Cooperation in the Finitely Repeated Prisoner's Dilemma. The Quarterly Journal of Economics, 133(1), $509-551$.

European Commission. 2014. DIRECTIVE OF THE EUROPEAN PARLIAMENT AND OF THE COUNCIL on certain rules governing actions for damages under national law for infringements of the competition law provisions of the Member States and of the European Union. 
Fudenberg, Drew, \& Tirole, Jean. 1991. Repeated Games. MIT Press.

Geradin, Damien, \& Grelier, Laurie-Anne. 2013. Cartel Damages Claims in the European Union: Have We Only Seen the Tip of the Iceberg? Tech. rept. SSRN Working Paper.

Green, Jonathan, \& McCall, Iona. 2009. Leniency and Civil claims. Competition Law Insight, 3-5.

Harrington, Joseph E. 2008. Optimal Corporate Leniency Programs. Journal of Industrial Economics, 56(2), 215-246.

Harsanyi, John., \& Selten, Reinhard. 1988. A General Theory of Equilibrium Selection in Games. Vol. 1. The MIT Press.

Komninos, Assimakis. 2011. Relationship between Public and Private Enforcement: quod Dei Deo, quod Caesaris Caesari. Tech. rept. 16th Annual EU Competition Law and Policy Workshop, European University Institute, Florence, 17-18 June 2011, p. 18.

Kortmann, Jeroen, \& Wesseling, Rein. 2013. Two Concerns Regarding the Draft Directive on Antitrust Damage Actions. Tech. rept. Competition Policy International Antitrust Chronicle (August 12).

Lande, Robert. 1993. Are Antitrust "Treble” Damages Really Single Damages? Ohio State Law Journal, 54, 115-174.

Lande, Robert H., \& Davis, Joshua P. 2011. Comparative Deterrence from Private Enforcement and Criminal Enforcement of the U.S. Antitrust Laws. Brigham Young University Law Review.

Leslie, Christopher. 2004. Trust, Distrust, and Antitrust. Texas Law Review, 82(3), $515-680$. 
Levenstein, Margaret C., \& Suslow, Valerie Y. 2006. What determines cartel success? Journal of Economic Literature, 44(1), 43-95.

MacCulloch, Angus, \& Wardhaugh, Bruce. 2012. The Baby and the Bathwater - The Relationship in Competition Law between Private Enforcement, Criminal Penalties, and Leniency Policy. Tech. rept. Paper Prepared for the CCP Conference - 14 June 2012.

Marshall, Robert, \& Marx, Leslie. 2012. The economics of collusion - cartels and bidding rings. The MIT Press.

Marvão, Catarina. 2015. The EU Leniency Programme and Recidivism. Review of Industrial Organization, 49(1), 1-27.

Marvão, Catarina, \& Spagnolo, Giancarlo. 2015. Pros and cons of leniency, damages and screens. Competition Law and Policy Debate, 1(4), 47-59.

Marvão, Catarina, \& Spagnolo, Giancarlo. 2018a. Cartels and Leniency: Taking stock of what we learnt. Chap. 4, pages 57-90 of: Corchón, Luis C., \& Marini, Marco A. (eds), Handbook of Game Theory and Industrial Organization. Edward Elgar.

Marvão, Catarina, \& Spagnolo, Giancarlo. 2018b. Should Price Fixers finally go to Prison? - Criminalization, Leniency inflation and Whistleblower rewards in the EU. SSRN Working Paper.

Marx, Leslie, Mezzetti, Claudio, \& Marshall, Robert. 2015. Antitrust Leniency with Multiproduct Colluders. American Economic Journal: Microeconomics, 7(3), 20540.

McAfee, R. Preston, Mialon, Hugo M., \& Mialon, Sue H. 2008. Private v. Public Antitrust Enforcement: A Strategic Analysis. Journal of Public Economics, 92(10-11), $1863-1875$. 
Motta, Massimo, \& Polo, Michele. 2003. Leniency programs and cartel prosecution. International Journal of Industrial Organization, 21(3), 347-379.

Segal, Ilya, \& Whinston, Micheal. 2007. Public vs Private Enforcement of Antitrust Law: A Survey. European Competition Law Review, 28, 306-315.

Shavell, Steven. 1997. The Fundamental Divergence Between the Private and the Social Motive to Use the Legal System. Journal of Legal Studies, 24(4), 575-.

Silbye, Frederik. 2012. A note on antitrust damages and leniency programs. European Journal of Law and Economics, 33(3), 691-699.

Spagnolo, Giancarlo. 2004. Divide et Impera: Optimal Leniency Programmes. CEPR Discussion Papers 4840. Center for Economic Policy Research, London.

Stigler, George. 1964. A Theory of Oligopoly. The Journal of Political Economy, 72(1), 44-61. 